\title{
ALHAJAS PARA UN PALACIO EN MADRID. ESCENOGRAFÍAS EFÍMERAS EN LA CASA DEL MARQUÉS DE COGOLLUDO EN EL OCASO DEL ANTIGUO RÉGIMEN (1785-1789)*
}

\author{
Precious Items for a Palace in Madrid. Ephemeral \\ Scenography in the House of the Marquis of Cogolludo \\ at the End of the Old Regime (1785-1789)
}

\author{
Raúl ROMERO MEDINA \\ Universidad Complutense de Madrid \\ raul.romero.medina@ucm.es
}

Fecha de recepción: 02/04/2020

Fecha de aceptación definitiva: 07/04/2021

RESUMEN: Luis María Fernández de Córdoba y Moncada, duque de Santisteban y marqués de Cogolludo, contribuyó a las causas festivas de la monarquía borbónica decorando con arquitecturas efímeras su palacio madrileño de la calle de Atocha. Gracias a un documento inédito de 1785, podemos conocer las alhajas que formaron parte de las escenografías levantadas por las dobles bodas de los infantes de España y Portugal. Su análisis iconográfico nos acerca al contexto de la fiesta y su magnificencia en el devenir de la sobriedad impuesta, en la majestad y el ornato, por las ideas de la Ilustración, contrarias al boato barroco, en el ocaso del Antiguo Régimen.

Palabras clave: alhajas; arquitectura efímera; marqués de Cogolludo; monarquía borbónica; Antiguo Régimen.

* Este trabajo participa de los proyectos de investigación I+D Corte y cortes en el Tardogótico Hispánico. Narrativa, memoria y sinergias en el lenguaje visual. REF: PGC2018-093822-B-I00 y Espacios del coleccionismo en la Casa de Austria 2: siglos XVI y XVII. REF: HAR2017-83094P. 
ABSTRACT: Luis María Fernández de Córdoba y Moncada, Duke of Santisteban and Marquis of Cogolludo, contributed to the festive causes of the Bourbon monarchy by decorating their ducal's palace on calle de Atocha with ephemeral architecture. Thanks to an unpublished document from 1785, we can know the precious items that were part of the scenographies created by the double weddings of the princes of Spain and Portugal. His iconographic analysis situates us in the context of the party and its magnificence during sobriety imposed, in majesty and ornament, by the ideas of the Enlightenment, contrary to Baroque pageantry, at the end of the Old Regime.

Key words: precious items; ephemeral architecture; Marquis of Cogolludo; Bourbon monarchy; Old Regime.

\section{INTRODUCCIÓN}

Hoy de Carlos adorna la Real frente, Sobre el timbre de Marte victorioso, Y el Lauro de la Paz mas delicioso, De amor una guirnalda reverente.

Hoy sus sienes se ven dichosamente Ceñidas con el lazo mas precioso, Quando el laurel, olivo y mirto hermoso A sus glorias se enlazan juntamente.

Pues Guerrero venciendo a las Naciones, Legislador rigiendo entrámbos Mundos, Queriendo en una unir tan alta gloria, Hoy enlaza los Reales corazones De España y Portugal: ¡lazos fecundos! Con que corona el Cielo su memoria ${ }^{1}$.

Entre el 27 y el 29 de marzo de 1785 la Villa y Corte de Madrid fue el escenario teatral que acogió las suntuosas celebraciones que tuvieron lugar con motivo de la doble unión sellada entre los infantes de España, doña Carlota Joaquina (hija de los príncipes de Asturias) y Gabriel (el hijo favorito de Carlos III) (Fig. 1) y los infantes de Portugal Juan y María Ana Victoria². Con este doble acontecimiento se culminaba una política matrimonial que perseguía aligerar las tensiones entre los dos países vecinos pero, sobre todo, estaba destinada a reducir el control que Inglaterra tenía sobre Portugal.

El esplendor con que la monarquía abordó este acontecimiento quedó reflejado especialmente en la Gaceta de Madrid que le dedicó el suplemento de 1 de abril de 1785 y que tituló Noticia de las Funciones y Fiestas con que se celebró el Desposorio de la Serenísima Señora Infanta Doña Carlota Joaquina, nieta del Rey, bija de los Príncipes Ntros. Sres. Con el Serenísimo Infante de Portugal Don Juan, bijo de la Reina y del Rey Fidelísimos ${ }^{3}$. Junto a ello, el acontecimiento fue recogido

1. Del Riego NúÑez, Eugenio Antonio. Poesías a las Reales Bodas de los Serenísimos Señores Infantes de España y Portugal. Madrid: Imprenta Real, 1785.

2. Estos acontecimientos fueron reflejados en varios medios impresos de la época que han sido recogidos en AlENDA Y MIRA, Jenaro. Relaciones de solemnidades y fiestas públicas de España. Madrid: Impresores de la Real Casa, 1903, tomo II, pp. 121-127. Citaremos de forma individual los que convengan al hilo del ensayo que narramos.

3. Gaceta de Madrid, 1 de abril de 1785, pp. 1-11. 


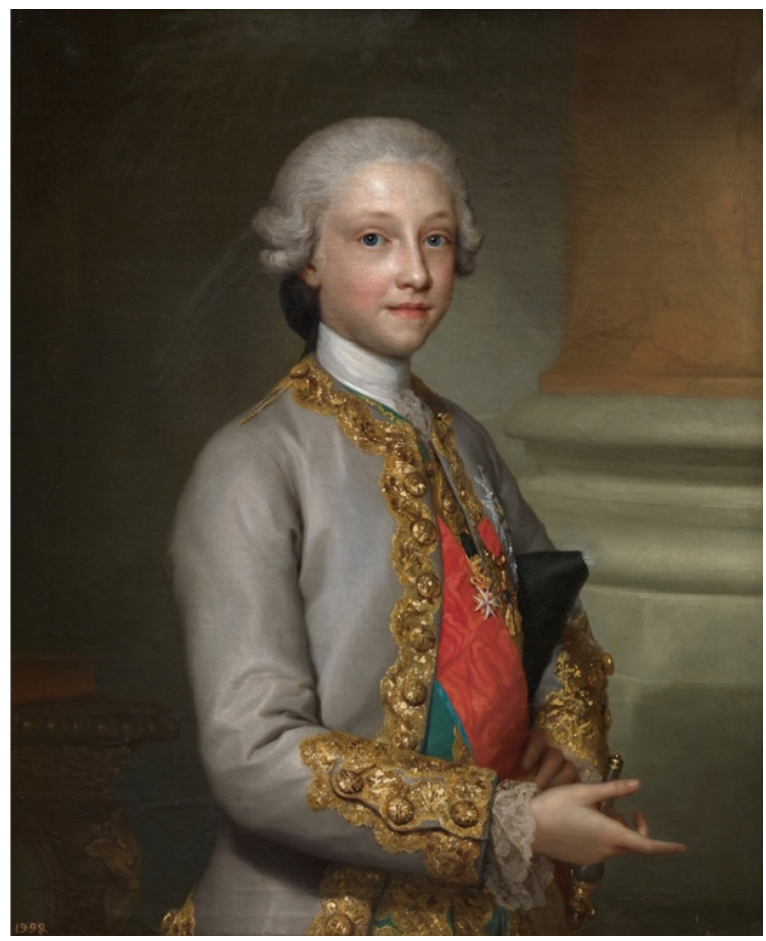

Fig. 1. Gabriel de Borbón y Sajonia, infante de España, 1767. Antón Rafael Mengs.

Óleo sobre lienzo, 82 x 69 cm. Museo Nacional del Prado, Madrid, Inv. P002196.

en el Memorial Literario ${ }^{4}$ de marzo de 1785 con la Noticia de algunas particularidades de las funciones celebradas en esta Corte, con motivo de los Desposorios de los Serenísimos Sres. Infantes de España y Portugal.

Particularmente, este último texto citado resulta de mayor interés por el detalle con el que se narra la deslumbrante recepción que ofreció el embajador de Portugal la noche del 27 de marzo y que terminó con un baile. En él se describen tanto el salón como las demás piezas que fueron decoradas para la ocasión, por Pedro de Arnal, con asuntos de temas mitológicos. Pero, sobre todo, esta noticia es importante por la forma tan prolífica con la que se describen las suntuosas arquitecturas efímeras que se levantaron en los principales edificios madrileños, los ubicados en la ruta que iba desde el Palacio Real a la basílica de Nuestra Señora

4. LARRIBA, Elisabel. "De l'usage de la gravure dans le Memorial literario (1784-1808)». El Argonauta Español, 2008, 5. [En línea] https://journals.openedition.org/argonauta/954. [Consultado el 21 de marzo de 2020].

5. Memorial Literario, n. ${ }^{\circ} 1316$, marzo de 1785 , pp. 332-355. 
de Atocha, donde el monarca Carlos III tenía que dar gracias a la Virgen en la tarde del 29 de marzo de $1785^{\circ}$.

De entre los principales adornos de esta carrera, se encontraba la fachada de la casa del marqués de Cogolludo, en la calle de Atocha, en la que se organizó una espléndida arquitectura efímera bajo la atenta supervisión del arquitecto Juan de Villanueva (1739-1811) ${ }^{7}$. Los testimonios de la época se refieren a ella señalando cómo «su adorno de perspectiva demostró el arte, el gusto y el dueño de la casa su munificencia en haber hecho colocar en su centro una hermosa fuente de tres caños, por los quales salían agua, leche y vino" ${ }^{8}$.

No fue la única ocasión en la que el palacio de la calle de Atocha lució en todo su esplendor. En 1789, con motivo de los ornatos públicos organizados para la exaltación al trono de Carlos IV y María Luisa de Parma, así como de la jura del príncipe de Asturias, Fernando9, los marqueses de Cogolludo engalanaron su fachada con los monogramas y retratos de los monarcas como centro del programa iconográfico ${ }^{10}$. Conservamos una estampa grabada en aguafuerte y buril por José Giraldo y García en la que se muestra la escenografía realizada por Felipe Fontana ${ }^{11}$ (Fig. 2). Sobre ella abundaremos más adelante.

6. Desde 1571 el monasterio de Nuestra Señora de Atocha había quedado fijado como el escenario que semanalmente visitaba el rey para el rezo de la Salve. Esta circunstancia tuvo una repercusión positiva en la mejora del entorno urbano y de las vías de entrada a Atocha. Como ha demostrado Concepción Lopezosa, la fiesta repercutió en el proceso de configuración urbano-arquitectónico del Madrid entre los siglos XV y XVIII. Algunas reflexiones en LoPEZOSA APARICIO, Concepción. «Fiesta oficial y configuración de la ciudad. El caso del madrileño Paseo del Pradom. Anales de Historia del Arte, 2002, 12, pp. 79-92.

7. Sobre los ornatos y arquitectura efímera de Juan de Villanueva puede verse el trabajo de MONTES SERRANO, Carlos. "El problema del estilo en la arquitectura madrileña del siglo XVIII». En SAMBRICIO, Carlos (ed.). Catálogo de la Exposición de Carlos III. Alcalde de Madrid (1788-1988). Madrid: Ayuntamiento de Madrid, 1988, pp. 449-478.

8. Guerra y Gazola, Antonio. Resumen de las sentencias y metros, que con motivo de los felices desposorios de los señores Don Juan, Infante de Portugal, con Doña Carlota Joaquina, Infanta de España, y D. Gabriel Antonio, Infante de España, con Doña Maria Ana Victoria, Infanta de Portugal, se han colocado en varias casas de las adornadas en la carrera que anduvo S.M. y AA. el dia 29 de Marzo de ida al Santuario de Atocha, y vuelta á su Real Palacio. Madrid: Imprenta Real, 1785, p. 10.

9. Sото CABA, Victoria. "Fiesta y ciudad en las noticias sobre la proclamación de Carlos IV". Espacio. Tiempo y Forma, Serie VII, Historia del Arte, 1990, 3, pp. 259-271. Morales Roca, Francisco José. "Mercedes concedidas con motivo de la exaltación al trono del Rey Carlos IV. Su entrada en Madrid, celebración de Cortes Generales y jura de don Fernando, Príncipe de Asturias (1. ${ }^{a}$ parte: Nobiliarias)». Hidalguia: la Revista de Genealogía, Nobleza y Armas, 2004, 304-305, pp. 463-474. IDEM. "Mercedes concedidas con motivo de la exaltación al trono del Rey Carlos IV. Su entrada en Madrid, celebración de Cortes Generales y jura de don Fernando, Príncipe de Asturias (2. " parte: Nobiliarias)». Hidalguía: la Revista de Genealogía, Nobleza y Armas, 2006, 319, pp. 835-874.

10. Sempere y Guarinos, J. Descripcion de los ornatos públicos con que la Corte de Madrid ha solemnizado la feliz exaltación al trono de los reyes nuestros señores Carlos IIII y Doña Luisa de Borbon y la jura del serenisimo señor Don Fernando, Principe de Asturias. Madrid: Imprenta Real, 1789.

11. Biblioteca Nacional de España (en adelante BNE) Inventario n. ${ }^{\circ}$ 70879. La estampa ha sido reproducida en varias ocasiones: SOCIEDAD Española DE Amigos DEL ARTE. Exposición del Antiguo 


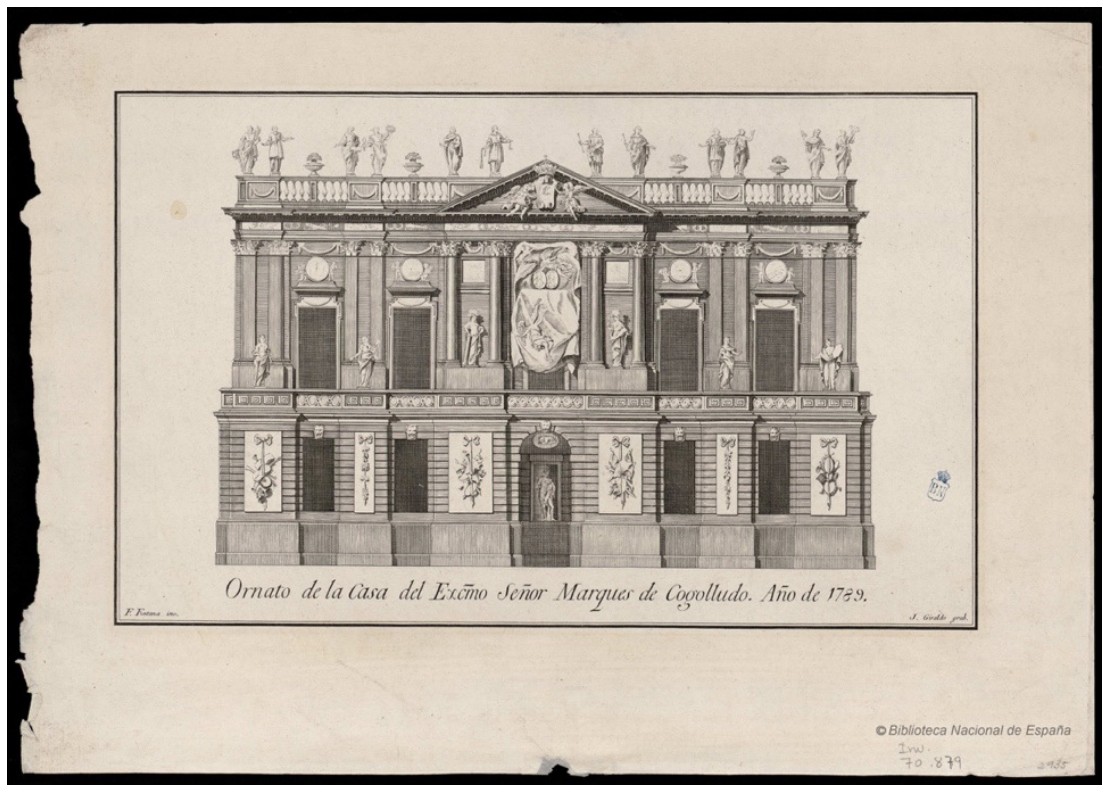

Figura 2. Ornato de la Casa del Excmo. Sr. Marqués de Cogolludo, 1789. José Giraldo García. Estampa: aguafuerte y buril; imagen 210 x 340, en h. de 295 x 420, pleg. en 295 x 195 mm. Publicada en Sempere y Guarinos (1789).

En el Archivo Ducal de Medinaceli ${ }^{12}$ se ha localizado un documento inédito que recoge todas las alhajas que se emplearon "para la función que dio el Excmo. Sr. Duque de Santistevan, marques de Cogolludo, con motivo de la exaltación al trono de sus Magestades». El documento firmado por Bedoya no tiene fecha, pero en el contexto del inventario levantado se refiere a los días 8, 9 y 10 de julio, y señala este último como domingo. Este dato resulta concluyente para poder determinar si las alhajas son referidas a la decoración realizada en la fachada del palacio en 1785 o en 1789. El 10 de julio que cayó en domingo corresponde al año de 1785, por ello si las celebraciones se llevaron a cabo en el mes de marzo parece coherente que en julio se levantara un inventario indicando cómo se habían

Madrid. Catálogo General Ilustrado. Madrid: Gráficas Reunidas, 1926. p. 291, n. ${ }^{\circ}$ 370. Madrid hasta 1875: testimonios de su historia. Madrid: Publicaciones Municipales, 1980. Bonet CorreA, A. "La última arquitectura efímera del Antiguo Régimen. Estudio Introductorio". En Descripción de los ornatos públicos de Madrid en la Coronación de Carlos IV. Barcelona: Gustavo Gili, 1983. CARrete, Juan et al. Catálogo del Gabinete de Estampas del Museo Municipal de Madrid. Madrid: Ayuntamiento de Madrid, 1985, vol. 1, p. 206.

12. Archivo Casa Ducal de Medinaceli (en adelante, ADM). Sección Archivo Histórico. Legajo n. ${ }^{\circ}$ 85. Inventarios, doc. 4. Vid. Apéndice Documental, doc. n. ${ }^{\circ} 1$. 
guardado estos artilugios. Ello justifica que el encabezamiento del documento pueda deberse a un error del escribano. En cualquier caso, como veremos, algunas de estas decoraciones pudieron ser reaprovechadas en 1789, año que coincide con la exaltación al trono de Carlos IV y María Luisa de Parma.

Se tiene constancia de que en el ámbito real fue frecuente reutilizar algunos elementos arquitectónicos que servían para tramar monumentos y decoraciones efímeras. Ello explica, como abordaremos en seguida, las críticas de Sempere y Guarinos a las decoraciones abigarradas y excesivas del palacio del marqués de Cogolludo en 1789, pues debieron nacer de esta reutilización un tanto forzosa. Por una breve relación que diera a conocer Paz y Meliá ${ }^{13}$, podemos comprobar cómo muchos de los objetos del inventario de alhajas de 1785 procedían de la colección de los marqueses de Cogolludo y que, por lo tanto, fueron utilizados de nuevo para la ocasión de la exaltación al trono de los reyes y la jura del príncipe de Asturias.

El documento de 1785 describe los artificios que se emplearon y que fueron posteriormente inventariados para ser trasladados a las casas de San Pedro y de San Jerónimo. Por ello, el análisis de esta fuente permite aproximarnos de forma exhaustiva al aparato escenográfico levantado, en cuya cornisa se colocaron además versos en octavas, y a la decoración de su interior. Su análisis iconográfico nos aproxima a la exaltación del linaje de los duques de Santisteban y marqueses de Cogolludo y su apoyo a la casa real en el contexto de la fiesta y su magnificencia en el devenir de la sobriedad impuesta, en la majestad y el ornato ${ }^{14}$, por las ideas de la Ilustración ${ }^{15}$, contrarias al boato barroco ${ }^{16}$.

13. Breve relación de lo actuado por el Excmo. Sr. D. Luis María de la Soledad Fernández de Córdoba, Marqués de Cogolludo, Duque de Santisteban, mi Señor, en las funciones de exaltación al Trono de sus Magestades de Don Carlos IV y D. ${ }^{a}$ María Luisa de Borbón, y jura del Príncipe de Asturias, celebradas en esta Corte en septiembre de 1789. PAZ Y MELIÁ, Antonio. Serie de los más importantes documentos del archivo y biblioteca del Exmo. Señor duque de Medinaceli. 1. a Serie Histórica. Madrid, 1915, pp. 264-271. Documento CLXXVII.

14. Benito García, Pilar et al. Carlos III. Majestad y Ornato en los escenarios del Rey Ilustrado. Madrid: Patrimonio Nacional, 2017.

15. Habitualmente la cronología del inicio de la Ilustración ha sido fijada en 1759, con la subida al trono de Carlos III, si bien se ha producido un interesante debate historiográfico que adelanta sus orígenes hasta la época de los llamados novatores, es decir, cuando se produce el relevo de los Austrias por los Borbones. Sobre este asunto: Álvarez de Miranda, Pedro. Palabras e ideas: el léxico de la Ilustración temprana en España (1680-1760). Madrid: Real Academia Española, 1992. PÉREz MAGALLón, Jesús. Construyendo la modernidad de la cultura española en el tiempo de los novatores (1675-1725). Madrid: CSIC, 2002

16. Bonet CorreA, A. "La arquitectura efímera del barroco en España». Norba. Revista de Arte, 1993, 13, pp. 23-70. IDEM. Fiesta, podery arquitectura: aproximación al Barroco Español. Madrid: Akal, 1990. GÁllego, Julián. "El Madrid de los Austrias: un urbanismo de teatro». Revista de Occidente, 1969, XXV, pp. 19-54. SOTO CABA, Victoria. El barroco efímero. Madrid: Historia 16, Cuadernos de Arte Español, 1992. Díaz BorQue, José María. Los espectáculos del teatro y de la fiesta en el siglo de Oro español. Madrid: Ediciones del Laberinto, 2002. 
ALHAJAS PARA UN PALACIO EN MADRID. ESCENOGRAFÍAS EFÍMERAS EN LA CASA DEL MARQUÉS...

En definitiva, gracias a esta fuente inédita, al material impreso en el que se describen los acontecimientos y al grabado conservado, podemos desmenuzar el tema al comparar dos escenografías efímeras de exaltación borbónica. En ellas se unen arquitectura efímera, fiesta pública y poder político en un momento histórico de transición en el que se enfrentaron el barroco, el rococó y la Ilustración, justo cuando el edificio «bien construido» del Antiguo Régimen se resquebraja.

\section{FUNCIONES Y FIESTAS DECRETADAS PARA UNA DOBLE UNIÓN}

Como hemos apuntado, el rey Carlos III señaló los días 27, 28 y 29 de marzo para que se celebrasen con toda solemnidad las funciones del desposorio de los infantes de España y Portugal. Así, el 27 por la mañana quedaba fijado como el día para la entrada y audiencia pública del embajador de Portugal para hacer la demanda solemne de la infanta Carlota, mientras que por la tarde se otorgarían las escrituras públicas de las capitulaciones matrimoniales y seguidamente para las del desposorio (Fig. 3).

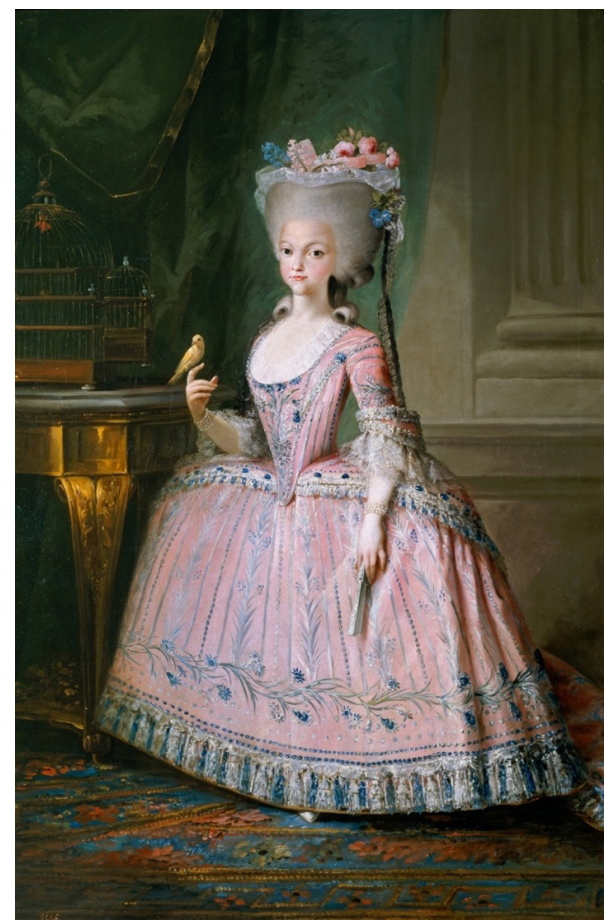

Fig. 3. Retrato de la infanta Carlota Joaquina, 1785. Mariano Salvador Maella. Óleo sobre lienzo, 177 x 116 cm. Museo Nacional del Prado, Madrid, Inv. P002440. 
Por su parte, el 28 fue destinado a los besamanos generales y la jornada del 29 se dividió entre la mañana, donde se celebrarían los besamanos de los consejos, y la tarde, en la que el rey acudiría públicamente a dar gracias al santuario de Nuestra Señora de Atocha. Tres días en los que se debía lucir uniforme de gala, así como realizar iluminaciones nocturnas.

Como era de esperar, los desposorios contaron con una preparación fastuosa. En realidad, el Madrid borbónico ya contaba con una amplia experiencia, pues la propia entrada de Carlos III $^{17}$ en la ciudad en 1760 -después de haber sido proclamado rey de España un año antes- había sido diseñada por el arquitecto y académico Ventura Rodríguez (1717-1785) $)^{18}$, quien preparó para la ocasión adornos, arcos efímeros, galerías, etc. ${ }^{19}$ (Fig. 4).

Las propias vallas de la carrera procesional estuvieron adornadas por trescientas cornucopias destinadas a alojar las luminarias. Como recientemente documenta Rodríguez Moya ${ }^{20}$, lo más espectacular fueron los fuegos artificiales que se idearon para la ocasión, que fueron diseñados por José de Vargas Torija, pirotécnico de Alcalá de Henares, y también por el pirotécnico José de Zamora.

Las fiestas de 1785 fueron casi una continuidad de la jornada festiva que Madrid vivía desde el año anterior pues, entre el 15 y el 17 de junio de 1784, la Villa celebraba con gran alegría el nacimiento de los infantes gemelos Carlos y Felipe -que habían venido al mundo en octubre de 1783- así como la Paz con Inglaterra y la expedición contra Argel. Como ha puesto de manifiesto Sambricio, la importancia de esta festividad reside en que introdujo un elemento de ruptura frente al modo anterior de concebir el espacio de la fiesta ${ }^{21}$. No solo se trató de un

17. GÓmEZ, Jesús. «Una conversación sobre la entrada real de Carlos III». Edad de Oro, 2007, XXXVI, pp. 267-286.

18. Conocemos la descripción de los ornatos publicada en esta fecha en la que se señalaba cómo la intención de los organizadores era "que el estilo se formase sobre el buen gusto Romano, por el cual se han nivelado todas las naciones europeas. por la cultura de la Corte del antiguo Imperio, y el gran aprecio de las Artes». Cit. Relación de los arcos, inscripciones y ornatos de la carrera, por donde ha de pasar el Rey nuestro Señor don Carlos III en su entrada pública. Madrid, 1760.

19. Como ha señalado Carlos Sambricio, la entrada del rey en Madrid, que se produjo el 13 de junio de 1760, implicó un cambio en los recorridos festivos y triunfales de la ciudad en los que el escenario de los Austrias quedó desplazado hacia un itinerario que buscaba pasar por los grandes proyectos arquitectónicos y urbanísticos que estaban cambiando la imagen de la ciudad. SAmBricio, Carlos. «Fiesta en Madrid durante el reinado de Carlos III». En SAmbricio Carlos (ed.). Catálogo de la Exposición de Carlos III, Alcalde de Madrid (1788-1988). Madrid: Ayuntamiento de Madrid, 1988, pp. 575-628. Sobre la arquitectura efímera de esta entrada pueden verse REESE, Thomas Ford. The architecture of Ventura Rodríguez. Nueva York, 1976, vol. 1, pp. 128-134. BotTinEAu, Yves. L'art de la cour dans l'Espagne des Lumières 1746-1808. París: Éditions De Boccard, 1986, pp. 275-279.

20. Rodríguez Moya, Inmaculada. "Tres siglos de máquinas ígneas. Los fuegos de artificio en los festejos de la Monarquía Española, siglos XVI al XVIII». En RodríguEZ Moya, Inmaculada (ed.). El Rey festivo. Palacios, jardines, mares y ríos como escenarios cortesanos (siglos XVI-XIX). Valencia: Universitat de València, 2019, pp. 153-174 (la cita en p. 67, nota n. ${ }^{\circ}$ 8).

21. Sambricio, Carlos. "Fiesta en Madrid durante el reinado...", p. 589. 


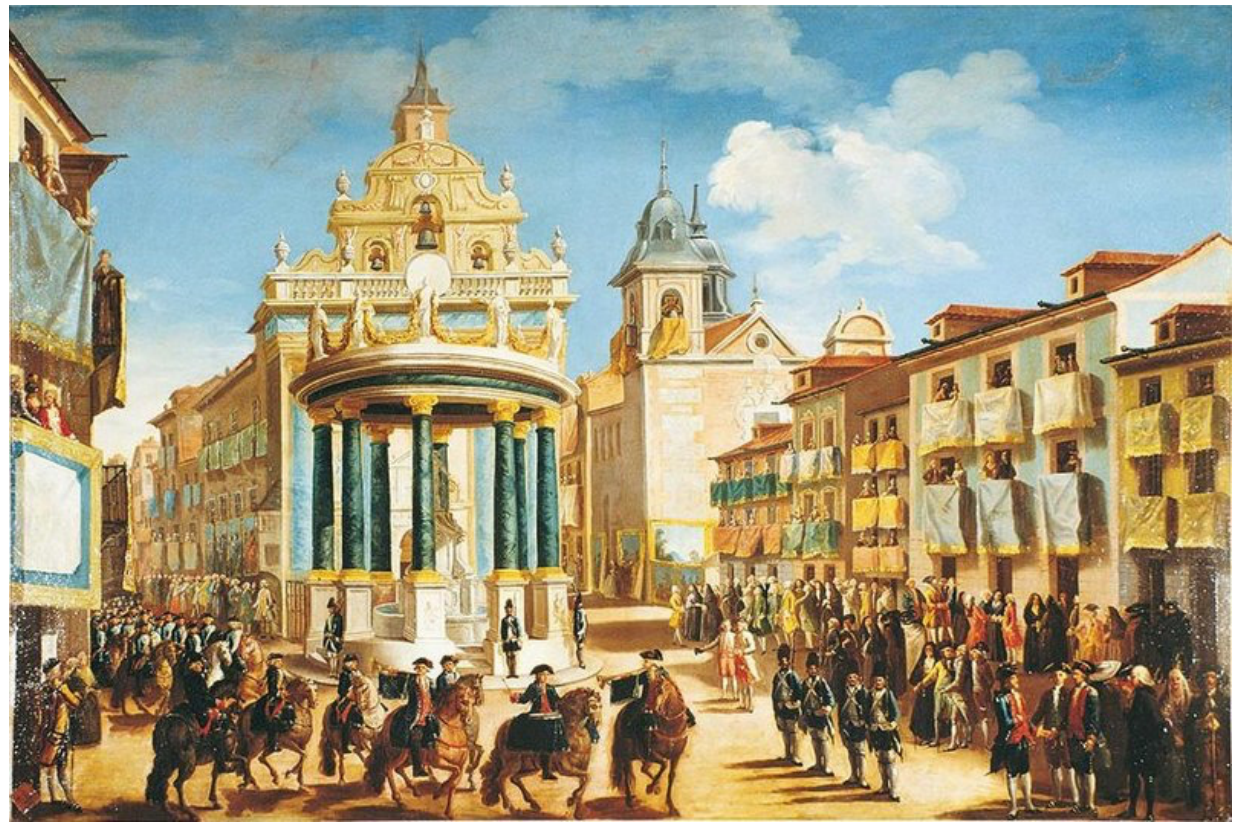

Fig. 4. Ornato de la puerta del Sol construido con motivo de la entrada real de Carlos III en Madrid en 1760, hacia 1763. Lorenzo Quirós, óleo sobre lienzo. Museo Municipal de Madrid.

acto cortesano, sino que la intención fue compartir la alegría con el pueblo, de ahí que Madrid iluminara sus calles durante tres días y que una mascarada recorriera la ciudad siguiendo diferentes itinerarios.

En esta ocasión no solo se engalanaron los edificios públicos y principales, sino que asistimos a una competencia entre las casas nobiliarias tanto por destacar en los ornatos privados, como en la organización de la fiesta más suntuosa con motivo de estas dobles efemérides de 1784. Un rico programa ornó la fachada del palacio del duque de Hijar ${ }^{22}$, pero también la del marqués de Montara en la calle del Prado, la casa del embajador de Francia, la del duque de Alba, la del duque de Villahermosa, la del duque de Medinaceli o las de los condes de Tepa o Benavente... a la que se unió la casa del marqués de Cogolludo.

22. Explicación del adorno que se ha puesto en la casa del Excelentísimo Señor Duque de Híjar en las Fiestas que celebra Madrid con motivo del feliz nacimiento de los dos Infantes Gemelos Carlos y Felipe, y el ajuste definitivo de la Paz con la Gran Bretaña. AlENDA y Mira, Jenaro. Relaciones de solemnidades y fiestas..., p. 113, n. $^{\circ} 2170$. 
La fiesta de 1784 fue un preludio de la organizada en 1785 donde el escenario fue la ciudad real ${ }^{23}$, no la ficticia y decorada del Madrid barroco, cuyos edificios se adornaron con motivos alegóricos que, en el caso de las casas nobiliarias, ensalzaban la idea del apoyo del linaje a la causa real. En términos de estilo este cambio se tradujo en unos fastos con escenarios ordenados y cerrados en los que la propia construcción de la imagen real evoluciona hacia una abstracción formal. No obstante, la parte más festiva de la conmemoración la constituía la jornada de la tarde del 29 de marzo, en donde se engalanaría la carrera por donde había de pasar el rey para ir al santuario de Atocha.

Así, el itinerario que llevaba Carlos III partía del Palacio Real, siguiendo por la plazuela de Santa María, la Platería, calle Mayor hasta la Puerta del Sol y de allí por la calle de las Carretas hasta la calle de Atocha para llegar al convento de la Virgen. El recorrido de regreso enfilaba toda la calle de Atocha a la Plaza Mayor, puerta de Guadalajara, la Platería y por la plazuela de Santa María hasta llegar al Palacio Real.

Los principales adornos de esta carrera real se concentraban sobre la Casa Real de los Consejos, la Casa de la Villa, la fachada de la casa del conde de Campomanes, la del marqués de Montealegre y conde de Oñate, la Real Casa de Correos -con varias alusiones al sacrificio de Himeneo-, la Imprenta Real y la casa del conde de Tepa en la calle de las Carretas, la casa del marqués de Cogolludo en la calle de Atocha y los Reales Hospitales Generales. Finalmente, desde allí y hasta el santuario de Atocha, todo el paseo se adornaba con 144 pilares a ambos lados en los que figuraba un globo con mecheros y rematados de antorchas para la iluminación. En el regreso de la comitiva las luminarias, la música y los morteretes, pequeñas piezas de artillería para las salvas, lucieron sobre estos edificios de tal modo que se «duplicó el gusto y la alegría de tan magníficas fiestas» ${ }^{24}$.

\section{El palacio de los duques de Santisteban y marqueses de Cogolludo}

En la tarde del 27 de marzo de 1785 el XII duque de Medinaceli acudía al Palacio Real de Madrid en calidad de testigo nombrado por Carlos III para el otorgamiento de la escritura de capitulaciones matrimoniales de los "Serenísimos Señores Infantes doña Carlota Joaquina y don Juan» ${ }^{25}$. En el gran Salón de los

23. El profesor Delfín Rodríguez ya señaló, y cito de forma textual, que aun cuando «las arquitecturas efímeras podrían haber servido para subrayar la monumentalidad de los diferentes edificios entre los que invariablemente se desarrollaban la "carrera real», lo que ponían en evidencia eran, por el contrario, su ánimo para "vestirlos», la aspiración de hacer real lo que no era sino una referencia ideal”, RODRíGuEz RuIZ, Delfín. "Los lenguajes de la magnificencia: la arquitectura madrileña durante el reinado de Carlos III». En SAmbricio, Carlos (ed.). Carlos III, Alcalde de Madrid (1788-1988). Madrid: Ayuntamiento de Madrid, 1988, pp. 265-280 (la cita en p. 266).

24. Memorial Literario, n. ${ }^{\circ} 1316$, marzo de 1785, p. 355.

25. Gaceta de Madrid, 1 de abril de 1785, p. 5. 
Reinos, donde estaba el dosel, Pedro Alcántara Fernández de Córdoba y Moncada (1730-1789) se reunió con los otros cuatro testigos que iban de la parte del rey, a saber, el marqués de Valdecazarna, el marqués de Villena, el marqués de Montealegre y el duque de Uceda ${ }^{26}$.

El XII duque de Medinaceli no solo pertenecía a la vieja nobleza castellana medieval, sino que era caballero de la Orden del Toisón de Oro, Gran Cruz de la distinguida Orden de Carlos III, además de mayordomo mayor del rey. Este último cargo, que el de Medinaceli desempeñó entre 1781 y 1787, lo hacía responsable del cuidado de la organización de la real casa y patrimonio de la Corona de España. Ello quizá explique el hecho de que su primogénito tuviese que estar implicado en la causa preparando su palacio con escenografías efímeras, luminarias y una sobresaliente orquesta de música.

Luis María Fernández de Córdoba y Gonzaga (1749-1806) era el primogénito del XII duque de Medinaceli. Por tratarse del futuro heredero de la casa ducal de Medinaceli, le correspondía el título de XI marqués de Cogolludo. Su casamiento con Joaquina María de Benavides y Pacheco (1746-1805), quien heredó en 1782 el título de III duquesa de Santisteban del Puerto, lo hacía duque consorte de Santisteban del Puerto, ya que sería el hijo primogénito de este matrimonio el que heredaría el título de su madre y lo vincularía definitivamente a la casa de Medinaceli.

Como es conocido, en estos momentos, los duques de Medinaceli tenían como residencia en Madrid el palacio en el Prado de San Jerónimo ${ }^{27}$ y, además, una residencia en la calle de Atocha, como herencia de la casa marquesal de Aytona $^{28}$, agregada a la de Medinaceli en 1739 por el matrimonio entre el en ese momento futuro XI duque de Medinaceli, Luis Antonio Fernández de Córdoba y Spínola (1704-1768), y María Teresa de Moncada y Benavides (†1756), también a la fecha futura VII marquesa de Aytona.

26. Ibidem.

27. Este palacio tuvo su origen en un edificio levantado a comienzos del siglo XVII por el I duque de Lerma, Francisco Gómez de Sandoval y Rojas (1553-1625). Lopezosa ApAricio, Concepción. "La residencia del duque de Lerma en el Prado de San Jerónimo, traza de Gómez de Mora". Madrid, Revista de Arte, Geografía e Historia, 1998, 1, pp. 457-485. Después pasó a la casa ducal de Medinaceli en 1653, a través del enlace matrimonial contraído entre doña Catalina Antonia de Aragón, duquesa de Segorbe, Cardona y Lerma, con Juan Francisco de la Cerda y Enríquez de Ribera (1637-1691), VIII duque de Medinaceli. El edificio fue abandonado en 1893 y demolido poco después. GaYa NuÑo, Juan Antonio. La arquitectura española en sus monumentos desaparecidos. Madrid: Espasa-Calpe, 1961, pp. 367-368. Diversa planimetría del edificio, así como una breve descripción de su historia en SÁNCHEZ GonZÁlEZ, Antonio (ed.). El arte de la representación del espacio. Mapas y planos de la colección Medinaceli. Huelva: Universidad de Huelva, 2017, pp. 281-297.

28. La casa de los marqueses de Aytona fue una de las más importantes del principado de Cataluña con un buen número de estados y baronías, no ya solo catalanas, sino valencianas y aragonesas. Sobre este asunto y sobre los fondos documentales que reunió la casa de Aytona puede verse el trabajo de SÁnchez González, Antonio. "Baronía de los Moncada en los Reinos de la Corona de Aragón: Fondos documentales inéditos para su estudio». Aragón en la Edad Media, 2008, XX, pp. 737-755. 
Así, los duques de Santisteban y marqueses de Cogolludo tuvieron como residencia el palacio de la calle de Atocha. Pero, además, no hay que olvidar la casa grande de Santisteban que el linaje de los Benavides tuvo como morada principal frente a la parroquia madrileña de San Pedro el Viejo y con conexión a la calle del Nuncio, si bien en 1742 ya estaba convertida en una casa de postas ${ }^{29}$.

La residencia del marqués de Cogolludo ocupaba una gran manzana cuya fachada principal corría a lo largo de toda la calle de Atocha y continuaba volviendo por la plazuela de Antón Martín y la calle de la Magdalena. Tal y como se puede comprobar en la Topographia de Madrid realizada por Pedro Texeira en 1656, la fachada principal de la casa se situaba justo en frente del colegio de Nuestra Señora de Loreto (XLII), una residencia para niñas huérfanas fundada en 1585 por el rey Felipe II (Fig. 5).

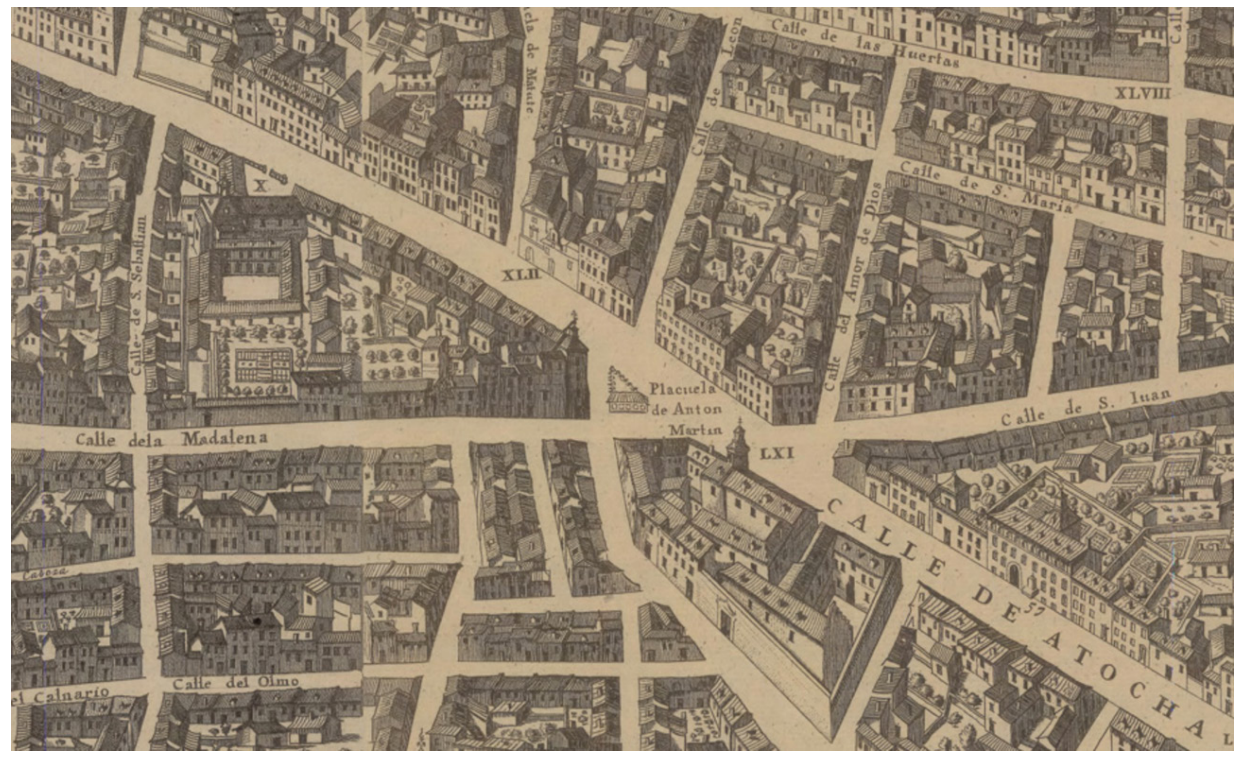

Fig. 5. Situación del palacio del marqués de Cogolludo en la calle de Atocha. Topographia de Madrid. Pedro Texeira, 1656.

29. La casa fue una adquisición de doña Leonor Dávila y Toledo, a finales del siglo XVI o principios del siglo XVII, cuyo hijo Francisco de Benavides y de la Cueva (1582-1640), VII conde de Santisteban, se instaló definitivamente en la corte. Después de ser casa de postas, obra de Gabriel González, se transformó a fines del siglo XIX en casa de vecinos, más otra en la esquina rehabilitada en 1952. Diversa planimetría del edificio, así como una breve descripción de su historia en SÁNCHEZ GonZÁlez, Antonio (ed.). El arte de la representación del espacio..., pp. 316-318. 
Como hemos señalado, esta residencia señorial era propiedad de la casa de Moncada, marqueses de Aytona, cuyos miembros habían prestado a lo largo de la Edad Moderna diversos servicios a la Corona. El acercamiento a la corte hizo necesaria una vivienda acorde con su rango. Tenemos constancia de que en ella ya falleció, el 17 de marzo de 1670, Guillermo Ramón de Moncada y Castro, IV marqués de Aytona, quien fuese gentilhombre de cámara y consejero de Estado de Felipe $\mathrm{IV}^{30}$, además de mayordomo mayor de la reina Mariana de Austria y miembro de la junta de gobierno del reino durante la minoría de edad de Carlos II $^{31}$. Quizá la vivienda fue adquirida por su padre Francisco de Moncada, III marqués de Aytona (1586-1635), quien desde 1626 era miembro del Consejo de Estado $^{32}$ y estuvo en los Países Bajos como embajador extraordinario junto a la infanta Isabel Clara Eugenia. Desde 1739 el linaje Moncada quedó unido a la casa ducal de Medinaceli, como ya hemos explicado, y la vivienda se convirtió en la residencia del primogénito, el marqués de Cogolludo.

Algo más de un año después de que el XI marqués de Cogolludo contrajera matrimonio con la III duquesa de Santisteban del Puerto ${ }^{33}$, este pidió licencia "para ejecutar cierta obra inmediata a su Casa principal» ${ }^{34}$. El marqués tenía la intención de incorporar al edificio unas accesorias ubicadas en la esquina de Atocha con Antón Martín. Efectivamente, en noviembre de 1765 la licencia incluía el diseño de alzado de las fachadas, la de Antón Martín, la de la Magdalena y la de Atocha, y el de su planta, firmados por Juan Antonio de Castro.

De las tres fachadas, nos interesa especialmente incidir en cómo era la principal, la de la calle de Atocha, pues fue el escenario de las arquitecturas efímeras desarrolladas en 1785. Además de señalar, como es evidente, el desnivel de la calle, vemos que se resolvía en tres alturas, separadas por impostas continuas, y buhardillas situadas sobre el tejado. La planta baja quedaba reforzada por un zócalo de cantería encuadrando la puerta principal, que aparece descentrada, sobre la que se sitúa un balcón que se remata con frontón triangular. La segunda y tercera planta se organizan con aberturas de balcones con huecos rectangulares simples (Fig. 6).

30. Garma y Durán, Francisco Javier. Theatro universal de España: descripción eclesiástica y secular de todos sus reynos y provincias. Barcelona: Mauro Martí, 1751, tomo IV, pp. 99-100.

31. RiBerA, Manuel Mariano. Genealogía de la Nobilissima familia de Cervellón. Barcelona: Pablo Campins, 1733, p. 145.

32. Garma y DuRán, Francisco Javier. Theatro universal de España ..., p. 91.

33. El matrimonio se celebró en la iglesia de San Pedro el Real de Madrid el 6 de febrero de 1764.

34. Archivo de Villa. ASA (Archivo Secretaría de Ayuntamiento) 1-44-104 (en adelante ADV). Cit. MARTínez MEdina, África. "La vivienda cortesana madrileña en el Reinado de Carlos III». En SAmbricio, Carlos (ed.). Carlos III, Alcalde de Madrid (1788-1988). Madrid: Ayuntamiento de Madrid, 1988, p. 362. 
ALHAJAS PARA UN PALACIO EN MADRID. ESCENOGRAFÍAS EFÍMERAS EN LA CASA DEL MARQUÉS..

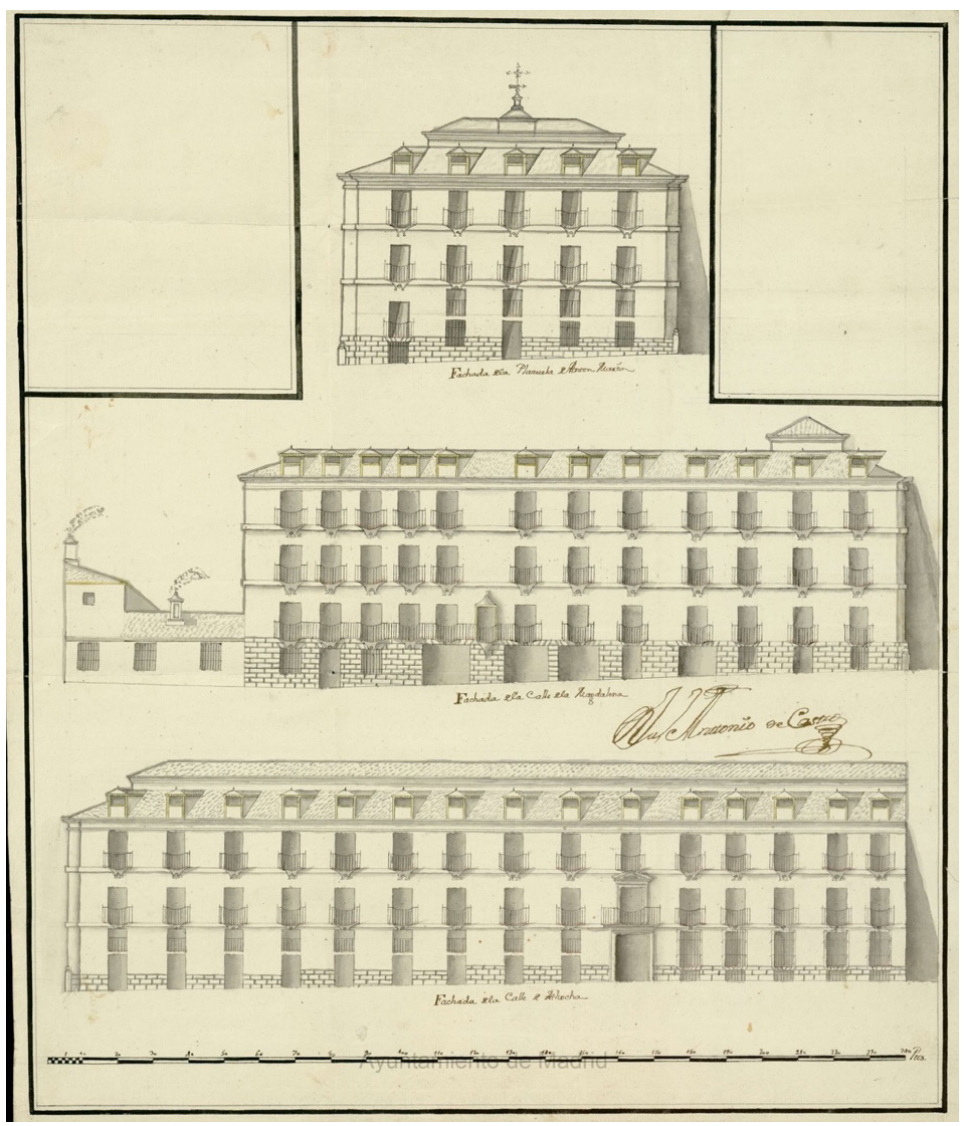

Fig. 6. Alzado del palacio del marqués de Cogolludo, 1765. Juan Antonio de Castro. ADV. ASA. 1-44-104.

Hay que señalar que en 1788 constan nuevas obras en el palacio a nivel de fachada, no solo en la de la Magdalena ${ }^{35}$, sino en la de Antón Martín ${ }^{36}$. En ellas intervino Manuel Bradi. Fue este mismo arquitecto quien en 1800 presentó un nuevo diseño para igualar y unificar la fachada principal del palacio y que fue

35. En este año se pide licencia para demoler la fachada que tienen a la calle de la Magdalena. ADV. ASA. 1-55-60. En él se incluye un diseño en alzado realizado por Manuel Bradi que pretendía alinear la fachada con otra casa que también les pertenecía. Cit. MARTínEz MEDinA, África. "La vivienda cortesana madrileña en el Reinado de Carlos III...., p. 364.

36. En un informe de 1800 se expresa claramente: «Y otra que provisionalmente se construyo a la frente de la plaza de Antón Martin [...]». ADV. ASA. 1-56-42. 
informado favorablemente por el arquitecto Juan de Villanueva ${ }^{37}$. No obstante, este proyecto nunca llegaría a ejecutarse ${ }^{38}$. En cualquier caso, el diseño de Bradi nos presenta una obra conectada con la distribución del alzado del Palacio Real de Madrid, es decir, cuerpo llagado horizontalmente, tratamiento del piso principal, mezaninos y remates abalaustrados ${ }^{39}$ (Fig. 7).

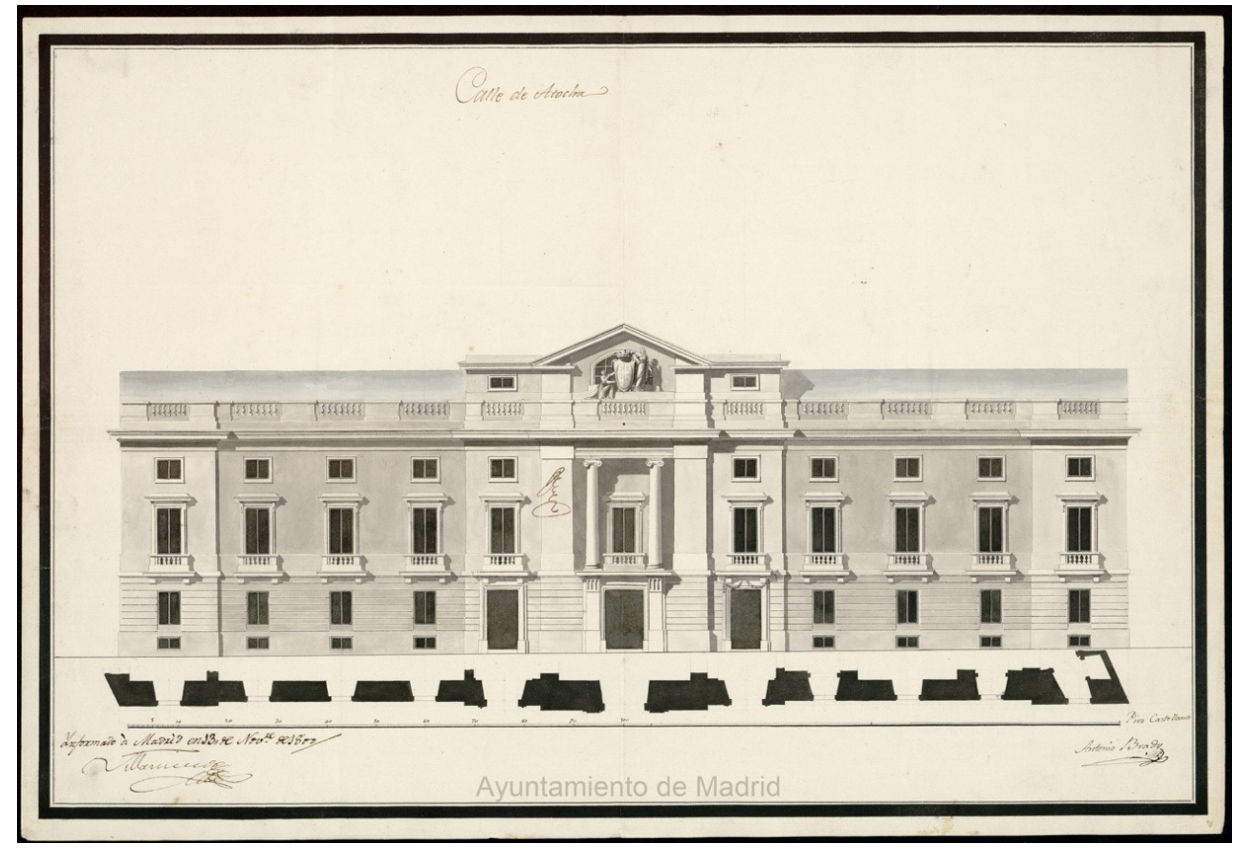

Fig. 7. Fachada del palacio de la calle de Atocha, 1800. Manuel Bradi. ADV. ASA. 1-56-42.

La intención de este proyecto era incorporar elementos nuevos puramente neoclásicos. Como ha señalado Navascués, ello se hace evidente en el dístilo jónico para lo que fue necesario improvisar un entablamento, y el remate del frontón sobre el ático, que dio como resultado un esquema bastante forzado ${ }^{40}$. El citado

37. ADV. ASA. 1-56-42.

38. NAVAscuÉs PalaCiO, Pedro. Palacios madrileños del siglo XVIII. Madrid: Artes Gráficas Municipales, 1978 , p. 18

39. Los lenguajes formales son muy diferentes, pues el proyecto de Bradi es austero, muy dependiente de los modelos de Juan de Villanueva, frente al barroco clasicista desarrollado por Sachetti en el Palacio Real madrileño. Sobre este asunto, véase NAVASCuÉs PALACiO, Pedro. "Sobre titulación y competencia de los arquitectos de Madrid (1775-1825)». Anales del Instituto de Estudios Madrileños, 1975, 11, pp. 123-136.

40. Ibidem, p. 135. 
autor pone en relación todo el cuerpo central bajo el frontón (con excepción del entablamento) con la obra, finalmente no ejecutada, que hizo Villanueva en 1789 para la fachada del oratorio del Caballero de Gracia de Madrid ${ }^{41}$.

\section{AlHajas Para un PALACIO EN MADrid: LAS ESCENOGRAFías EFÍMERAS (1785-1789)}

El inventario de alhajas de $1785^{42}$ es tan rico en detalles que nos permite conocer no solo la decoración levantada sobre la fachada de la calle de Atocha, sino todo el atrezzo interior del palacio. No obstante, gracias a la noticia de las funciones celebradas en $1785^{43}$ nos podemos acercar con detalle a la fachada ficticia que Juan de Villanueva ideó para la ocasión. Estas vistosas arquitecturas efímeras estaban destinadas a enmascarar, como si se tratase de un telón, la vista que producía una destartalada fachada nobiliaria. ¿Cómo se ideó este despliegue aparatoso?

En primer lugar, en el piso bajo se organizó un pórtico de seis columnas con sus pedestales y sus cornisas adornadas con triglifos y metopas cuyos extremos eran las puertas de la casa, como sabemos, una verdadera y otra fingida ${ }^{44}$. En el intercolumnio de en medio se colocó un jarrón rematado por dos palomas que frotaban sus picos y atadas por una cinta de cuyo extremo tiraba un Cupido puesto de rodillas al otro lado del jarrón y del otro un Cupido con carcax a la espalda y arco en la mano derecha. Justo debajo de este vaso se puso una fuente con tres caños que destilaban vino, agua y leche. Mediante lienzo pintado se simuló una balaustrada sobre las ventanas de los balcones y en medio de cada una se puso el blasón de la casa, es decir, un águila de cuyo pico colgaban festones de palmas doradas y ramos blancos de olivo formando guirnaldas. El balcón de cada extremo se coronó con un águila imperial en cuyo vientre se leían las cifras de Cogolludo y Santisteban.

En el segundo cuerpo de la fachada se colocaron sobre los balcones tarjetones cuadrilongos sobre los que se pintaron varios juegos de cupidos y alusiones al Himeneo. En los entrepaños lucían festones dorados de rosas y flores y varios trofeos ${ }^{45}$, así como bajorrelieves, que estaban sostenidos en tramos por argollas

41. Ibidem.

42. ADM. Sección Archivo Histórico. Legajo n. ${ }^{\circ}$ 85. Inventarios, doc. 4. Apéndice Documental, doc. 1.

43. Memorial Literario, n. ${ }^{\circ} 1316$, marzo de 1785 , pp. 332-355.

44. Sobre cada una de estas puertas se colocaron dos octavas reales: « $1^{\mathrm{a}}$. No al amor paternal en este día El amor fraternal dispute glorias, Que el amor conyugal los desafía Con leyes de derecho más notorias: Mío (dice) es tal bien la dicha es mía. Víctimas propias son tales memorias: Carlota vence y Juan su fe cautiva; Pues si el día es de Amor. solo Amor viva. $2^{\text {a }}$. Todo es amor quanto la vista ofrece, Hoy amor vence, Amor hoy reyna solo, Y en duplicados lazos aparece Venturoso y feliz de polo a polo; En Gabriel, y en María Ana reverdece El más alto laurel que envidia Apolo: Gócese Portugal de tanta gloria; pues España le paga la Victoria». Memorial Literario, n. ${ }^{\circ}$ 1316, marzo de 1785, p. 351.

45. Fueron seis como describe el inventario: «En esta pieza estan colocados los seis colgantes o trofeos que sirvieron de adorno en la fachada y una cora". ADM. Sección Archivo Histórico. Legajo n. ${ }^{\circ}$ 85. Inventarios, doc. 4. Apéndice Documental, doc. 1. 
que salían de la boca de cabezas de leones. Por último, en el entrepaño de los dos pisos y en el balaustre principal se pusieron mecheros con hachas ${ }^{46} \mathrm{y}$ en $\operatorname{los}$ intercolumnios del piso bajo se ubicaron las arañas para la iluminación ${ }^{47}$.

Hasta aquí todo lo que nos dicen las crónicas de la época. El documento de 1785 nos especifica que además en la fachada se pusieron siete figuras y en la puerta principal una imagen de Hércules, junto con cuatro medallones y un león.

No cabe la menor duda de que esta arquitectura ficticia se hizo con materiales maleables y de escasa consistencia como maderas, telas, cartón, papeles, cal y escayola. Para hacer todo el montaje fue necesario contar con veintiséis garruchas y diecinueve tiros de soga de cáñamo ${ }^{48}$. Ello corrobora que estas arquitecturas estaban pensadas de forma provisional, es decir, mientras durasen las ceremonias y fastos reales.

Para el desarrollo de estas fiestas era también importante el atrezzo interno del palacio, teniendo en cuenta que el marqués de Cogolludo ofrecería un refresco para la ocasión, una serenata y una cena de gala. En todo ello había una clara intención de exaltar la figura del príncipe y a la vez servir de símbolo del poder triunfante de la monarquía ilustrada, así como una muestra del esplendor del linaje Fernández de Córdoba-Benavides. Todo ello parece que se llevó a cabo en los amplios cuartos bajos del palacio de Atocha, una larguísima galería de doble crujía que discurría por la calle principal volviendo sobre la plaza de Antón Martín (Fig. 8).

Para la decoración de estas amplias crujías se necesitó de toda una suerte de elementos de tapicería para revestir con magnificencia el espacio de la fiesta cortesana, pues había que entelar los $\operatorname{muros}^{49}$. El inventario de $1785^{50}$ nos detalla todas las colgaduras que se emplearon con los más ricos tejidos de tafetán, algunos guarnecidos con glasés de oro para darle mayor brillo y otros bordados de varios colores con platillas y brichos. De entre ellas, destacan cuarenta y cinco sobrepuertas o portières que eran accesorios de tapicería con diversa temática y que

46. "10 acheros con su mechero que sirvieron en la fachada». ADM. Sección Archivo Histórico. Legajo n. ${ }^{\circ}$ 85. Inventarios, doc. 4. Apéndice Documental, doc. 1.

47. Se tiene constancia de que para la función se emplearon un total de 49 de las 50 arañas que tenía el marqués de Cogolludo entre la casa de San Pedro y Atocha. Algunas de ellas fueron prestadas al embajador de Portugal y una de ellas se quebró. Al terminar los fastos, 27 quedaron en el salón del palacio de Atocha y las 22 restantes se guardaron en la alcoba principal del marqués en la casa de San Pedro. ADM. Sección Archivo Histórico. Legajo n. ${ }^{\circ}$ 85. Inventarios, doc. 4. Apéndice Documental, doc. 1 .

48. "26 garruchas de madera que sirvieron para subir los adornos de la fachada y salon. 19 tiros de soga de cañamo de diferentes tamaños que sirvieron para la expresada fachada y salón». ADM. Sección Archivo Histórico. Legajo n. ${ }^{\circ}$ 85. Inventarios, doc. 4. Apéndice Documental, doc. 1.

49. ÁGreda Pino, Ana María. «Entelar el muro: los revestimientos textiles en la arquitectura occidental». En GÓMEZ URDÁÑEZ, Carmen (coord.). Sobre el color en el acabado de la arquitectura bistórica. Zaragoza: Universidad de Zaragoza, 2013, pp. 273-330. Sobre los amueblamientos textiles en época de Carlos III puede verse el texto de SANCHO, José Luis. "Vestir palacio a la moda. Carlos III y el amueblamiento textil del Palacio Real de Madrid». Archivo Español de Arte, 2000, 290, pp. 117-131.

50. ADM. Sección Archivo Histórico. Legajo n. ${ }^{\circ}$ 85. Inventarios, doc. 4. Apéndice Documental, doc. 1 . 
habitualmente se colocaban en los tramos de muros libres que quedaban entre los vanos y los techos de la sala. Junto a ello, se necesitaron ochenta y nueve cortinas blancas de tafetán y glasé dorado para guarnecer los ventanales del palacio, en un claro gusto por los tintes claros, alegres y luminosos. Además, se registran sesenta y tres paños de tafetán en varios colores bordados con platillas y brichos, varios bordados que sirvieron como frisos y algunos retales que complementaron las colgaduras de la sala, a la que se le añadieron guirnaldas con cintas y flores. No cabe duda de que para desplegar todo este fasto hubo que emplear parte del ajuar que habitualmente permanecía guardado o que se encontraba distribuido entre la casa de San Pedro y el palacio de San Jerónimo. Al acabar las fiestas, gran parte de estas tapicerías fueron guardadas en los tres grandes arcones que cita el inventario de $1785^{51}$.

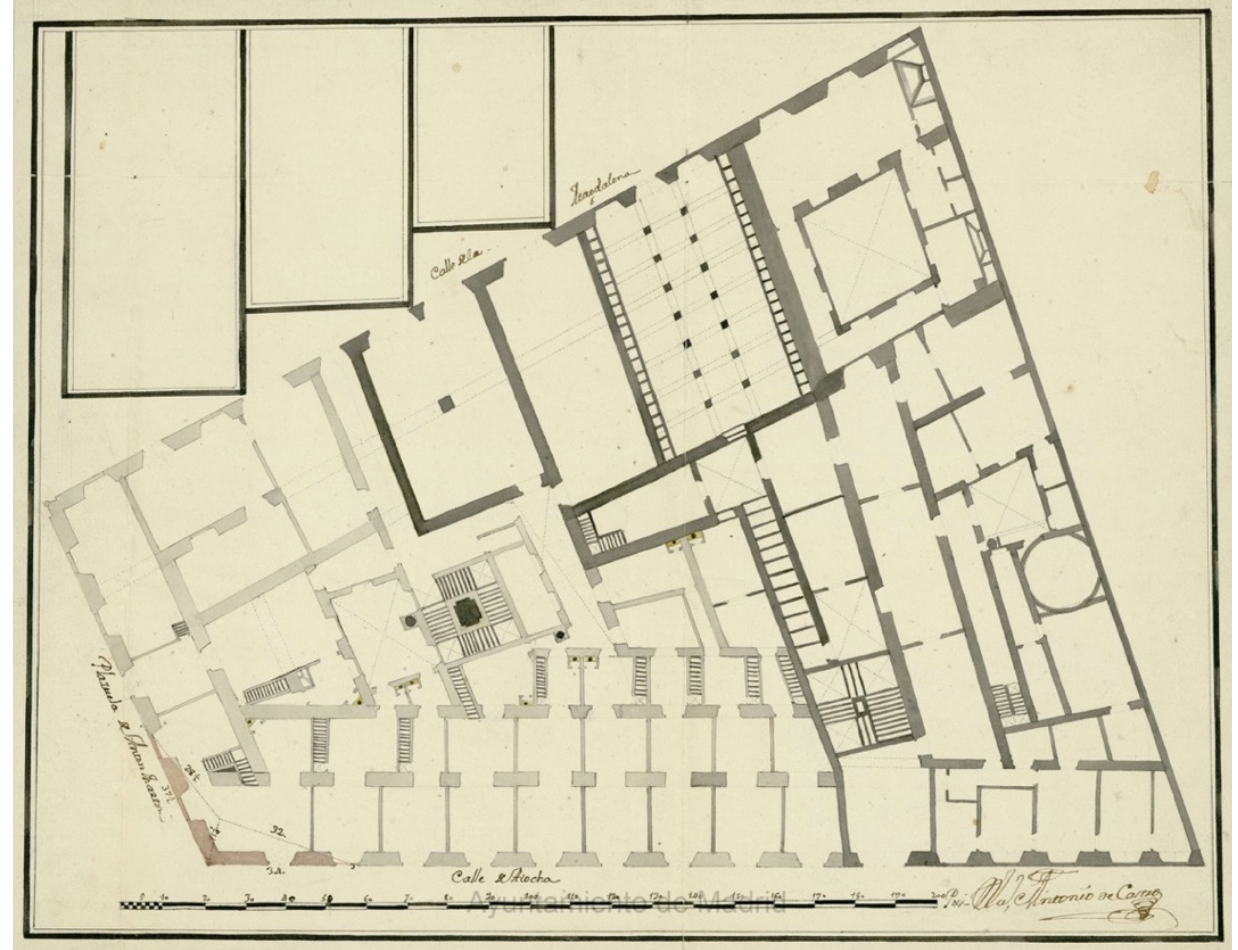

Fig. 8. Planta de la casa del marqués de Cogolludo, 1765. Juan Antonio de Castro. ADV. ASA. 1-44-104.

51. Ibidem. 
Los tejidos contribuían a crear una escenografía teatral que ayudaban a enfatizar los acontecimientos solemnes, sobre todo porque podían recogerse y desplegarse al antojo o incluso para acotar un espacio que interesaba, alternativamente, esconder y/o revelar ${ }^{52}$. Es por ello por lo que los objetos complementarios para recogerlos, que se ornaban con bolitas de plata y oro falso o los diecinueve boliches para las borlas, aparecen en el inventario. Sin duda, se trataba de modificar el aspecto habitual de la sala y acondicionarla simbólicamente para la ocasión.

La calidez de estas salas se vio reforzada con el blanco en combinación con los tonos claros: rosas, amarillos, azules, verdes o grises, pues remarcaban la idea de ceremonia de enlace marital. Es la época de las tonalidades pastel que triunfan en un Madrid urbano. Así, en el espacio destinado a la servidumbre de los reyes se colocó una rica alfombra o paño de glasé de oro moteada con dos órdenes de galón de oro brillante y ocho borlas colocadas en sus extremos. Sobre ella, se dispusieron los dos tronos reales tapizados en tafetán blanco y guarnecidos a juego con los citados órdenes de la alfombra ${ }^{53}$. Aun así, el desglose del programa de las fiestas de 1785 no refleja la presencia de la pareja real en las casas de Cogolludo, celebración que sí presidieron en 1789.

Para la decoración de la sala no se escatimó en detalles. Resultan francamente interesantes las cuarenta y tres sobrepuertas «de madera dadas de color de la porcelana con sus varillas y tornillos" que debieron de ser utilizadas a manera de sobradillos sobre las puertas interiores de los aposentos del cuarto bajo, de la cual pendían las cortinas de tafetán blanco descritas.

Alrededor de las paredes de la sala se dispusieron treinta y dos arandelas "finas dadas de color con sus flores imitando China" y otras 132 del color de la porcelana "para mecheros", es decir, para el canutillo donde se pone la mecha para alumbrar o encender lumbre ${ }^{54}$. Durante el reinado de Carlos III, el gusto oriental en el amueblamiento y en la decoración de los diferentes espacios palatinos se materializó en varios tipos de adornos ${ }^{55}$. Así, estas arandelas debieron ser pintadas imitando los motivos vegetales de los llamados como tejidos pequines, es decir, adornos de rameados de hojarascas y flores acompañados de pájaros que eran impresos en tinta china y posteriormente se coloreaban al temple con vivos colores.

52. PÉrez Monzón, O. "Ceremonias regias en la Castilla medieval. A propósito del llamado libro de la Coronación de los Reyes de Castilla y Aragón». Archivo Español de Arte, 2010, 332, p. 319.

53. Sobre la función y el decoro que ejercía el mobiliario en la época de Carlos III puede consultarse el trabajo de SANCHO, José Luis. "Función y decoro. El mobiliario del palacio real de Madrid bajo Carlos III". Libros de la Corte, 2018, 10, pp. 258-310.

54. De hecho, parte de la iluminación de la sala y de la fachada se hizo con hachas o velas de cera grande y gruesa: "12 acheres grandes de tres mecheros; 10 acheros con su mechero que sirvieron en la fachada». ADM. Sección Archivo Histórico. Legajo n. ${ }^{\circ}$ 85. Inventarios, doc. 4. Apéndice Documental, doc. 1 .

55. Sobre este asunto Benito García, Pilar. "Chinoiseries». En Carlos III. Majestad y Ornato en los escenarios del rey ilustrado. Madrid: Patrimonio Nacional, 2017, pp. 297-313. 
Para la comida de esta gran celebración se adornó la mesa con piezas de extraordinario tamaño y riqueza y, a juzgar por los datos que nos ofrece el inventario, se utilizó el servicio francés. De entre los monumentales adornos de carácter fijo destacan los diseños arquitectónicos que se conocen con el nombre de dessert, y que se disponían en el centro de la mesa, sobre un tablero. Como se ha señalado, la importancia que adquirieron estos adornos de mesa dio lugar a la creación de un nuevo oficio dentro de los de Boca, llamado de Ramillete y que finalmente será el encargado del montaje de las mesas reales ${ }^{56}$ y de la custodia de los objetos en ellas empleadas ${ }^{57}$.

El marqués de Cogolludo quiso impresionar a sus invitados con unos voluminosos ingenios decididamente arquitectónicos, cuya finalidad original era servir de decoración, si bien también resultaban francamente útiles para colocar con cierto orden las especias, las aceiteras, los saleros, etc. Era la más clara representación del lujo y para ello se acudía generalmente a metales preciosos, porcelana, piedra dura o bronce. Así, entre los conjuntos decorativos de gala que menciona el inventario destacan el dessert llamado de las fuentes, el de la feria, el de la bacanal o el nombrado "el maio" ${ }^{58}$. ¿Cómo eran estas piezas?

Desgraciadamente no se han conservado, pero el ejemplo más claro de que disponemos hoy en el Palacio Real de Madrid y el Museo Arqueológico Nacional es el realizado por Luigi Valadier ${ }^{59}$ en Roma y que fue vendido en 1786 al príncipe de Asturias ${ }^{60}$, el futuro Carlos IV $^{61}$ (Fig. 9). El dessert fue confeccionado en bronce dorado, con camafeos y piedras duras, sobre cuyos tableros iban templetes, columnas, obeliscos y otras piezas arquitectónicas de estilo neoclásico, que le confería una imagen de la Roma antigua. En este sentido, también destaca el que imita las carreras de cuadrigas o el monumental egipcio que se conserva en la Casa de Wellington, en Londres, confeccionado en porcelana de Sèvres.

56. Simón PAlmer, María del Carmen. «Evolución del gusto en la Mesa Real». En GARCía FernáNDEZ, María Soledad (ed.). Tres siglos de formas y objetos en los palacios y monasterios reales. En torno a la mesa. Madrid: Patrimonio Nacional, 2000, p. 31.

57. Martín, Fernando A. "Etiquetas y servicios en la Mesa Real». En GARCía Fernández, María Soledad (ed.). Tres siglos de formas y objetos en los palacios y monasterios reales. En torno a la mesa. Madrid: Patrimonio Nacional, 2000, p. 56.

58. ADM. Sección Archivo Histórico. Legajo n. ${ }^{\circ}$ 85. Inventarios, doc. 4. Apéndice Documental, doc. 1.

59. GonZÁlez Palacios, Alvar. Luigi Valadier. Nueva York: The Frick Collection, 2018.

60. Sobre las artes en la corte de Carlos IV son imprescindibles los textos contenidos en el catálogo de la exposición de 2009, principalmente el de SANCHO, José Luis. «iTan perfectas como corresponde al gusto y grandeza de sus Majestades». Las artes en la corte de Carlos IV». En SANCHO, José Luis et al. (eds.). Carlos IV, mecenas y coleccionista. Catálogo de la Exposición. Madrid: Patrimonio Nacional, 2009, pp. 15-52.

61. Herrero, María Jesús. "Dessert del Príncipe Carlos (Carlos IV)». En García Fernández, María Soledad (ed.). Tres siglos de formas y objetos en los palacios y monasterios reales. En torno a la mesa. Madrid: Patrimonio Nacional, 2000, p. 69. 


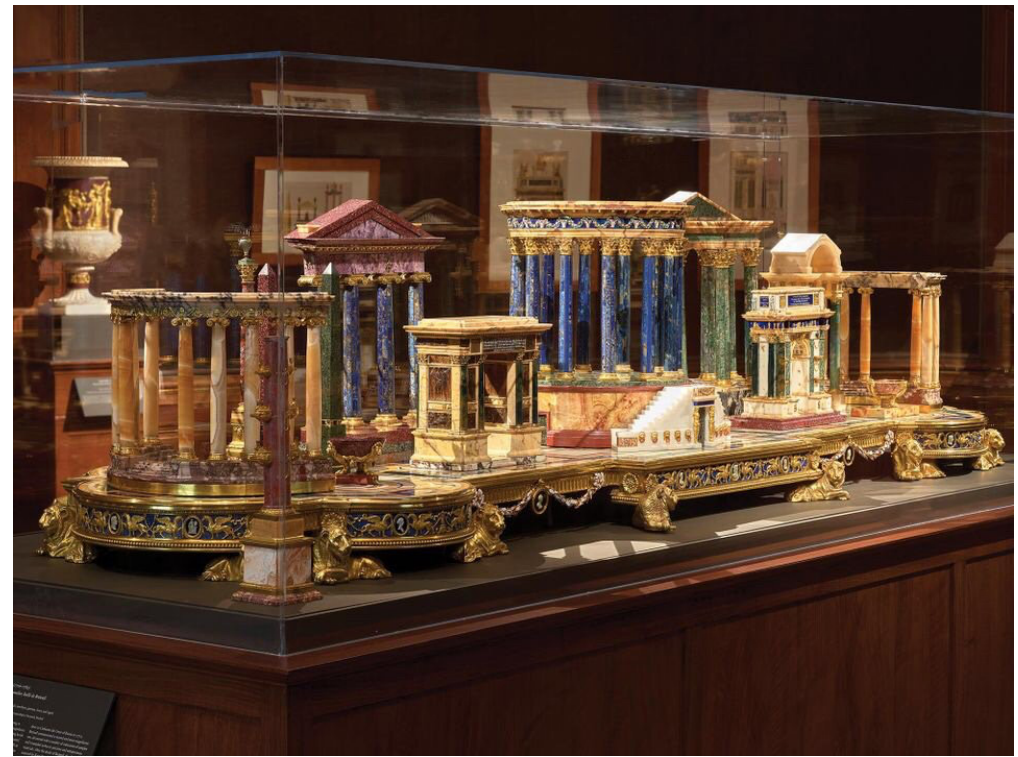

Fig. 9. Dessert que perteneció a Carlos IV, c. 1778. Luigi Valadier. Patrimonio Nacional, Madrid.

En cualquier caso, la descripción que nos ofrece el inventario de 1785 permite conocer cómo eran esos desserts. Así, el llamado de las fuentes estaba conformado por cinco tableros y cuatro basas que contenían los grupos. Normalmente estos plateau, o base de piedras duras, bronce, dorado y esmalte, eran sobre los que se distribuían los diferentes elementos. Este centro de mesa disponía de un templo octástilo e iba acompañado por once grandes figuras, probablemente una estructura imaginaria dedicada a algún dios romano. Haciendo gala de su nombre tenía catorce fuentes, que eran platos grandes, más o menos hondos, que se usaban para servir los alimentos, además de setenta y siete vasos. Pero también iba acompañado de dieciséis árboles frutales, 110 figuras de estatuas, setenta y cuatro figuras con traje y "Ocho pertierros que sirvieron de figuras al paseo del dessert ${ }^{62}$. Probablemente se trate del mismo que refiere el documento de 1789 como dessert del jardín, que incluye alegorías de los dioses Neptuno y Ceres y un niño con peces en las manos echando agua por sus bocas y que tuvo capacidad para setenta cubiertos, ochenta y cuatro platos de cocina, 116 de pastelería y setenta de repostería ${ }^{63}$.

62. ADM. Sección Archivo Histórico. Legajo n. ${ }^{\circ}$ 85. Inventarios, doc. 4. Apéndice Documental, doc. 1.

63. PaZ y Meliá, Antonio. Serie de los más importantes..., p. 267. 
El dessert llamado de maio pudo deber su nombre a los dos ramos o enramadas que contenía el centro de mesa. Los mayos los solían poner los novios a las puertas de las novias, de ahí el carácter nupcial de este servicio de mesa. Estaba formado de tres piezas o plateau sobre las que se distribuían sesenta y seis figuras y treinta y cuatro pedestales con las fichas. Este fue reutilizado en las celebraciones de 1789 y se señala que tenía en medio el triunfo de la diosa Ceres, imitando el mármol, rodeado de vasos y esfinges guarnecidos de figuras alemanas que representaban los bailes llamados "el Taich y la Fontana", unos con su coro de música y otros celebrando banquete. Tuvo capacidad para treinta cubiertos y se sirvieron en él cuarenta platos de cocina, treinta y dos de pastelería y veintiocho de repostería ${ }^{64}$.

Por su parte, el dessert de la feria estaba formado por cinco tableros, dieciocho basas con sus vasos, setenta y seis trajes españoles y de otras clases, varias mesitas de quincallería y hasta incluía una glorieta con su pirámide. Este fue reutilizado en las celebraciones de 1789 y se señala que en sus extremos había dos tablados donde figuraba un sacamuelas con sus herramientas y uno que vendía bálsamo y abajo varios puestos de género con personas de diversos trajes, comprando, paseando o bailando. Fue una mesa para cuarenta y ocho cubiertos, con ochenta platos de cocina, sesenta de pastelería y cincuenta y dos de repostería ${ }^{65}$.

Por último, los cinco tableros del dessert llamado la bacanal deben su nombre a los dos bailes de ménades o bacantes que incluía. Estaba formado de cincuenta y seis figuras de traje y de otras cuarenta y tres situadas en una suerte de emparrado; además de cuarenta y cuatro basas con sus pedestales y dos pirámides ${ }^{66}$. En 1789 se describe como el Triunfo de Baco y deja claro que estaba formado por un emparrado en medio del cual había cuatro bustos de bacanales. Formado por sesenta cubiertos, fue servido con ochenta y cuatro platos de cocina, ochenta y dos de pastelería y sesenta y ocho de repostería ${ }^{67}$.

Como podemos comprobar, estos desserts fueron guardados dentro de los cuatro cajones que señala el inventario, colocando todas las figuras debajo de sus respectivos tableros con el fin de protegerlas. Estos cajones se distribuyeron en las distintas estancias de la casa de San Pedro. Pero también se guardaron en un cajoncito figuras sobrantes. No obstante, el inventario nos ofrece una información sensiblemente importante al señalar que en la cena de gala no solo se utilizaron estos cuatro centros de mesa, sino que hubo dos más aunque fueron «en pastillajes». Evidentemente, con ello se refiere a que hubo monumentales pasteles de variado diseño que, si bien en un principio sirvieron como adorno de la mesa, era

64. PAZ y Meliá, Antonio. Serie de los más importantes..., p. 267.

65. PaZ y Meliá, Antonio. Serie de los más importantes..., pp. 268-269.

66. El inventario señala que faltaban dos figuras y un pedestal. ADM. Sección Archivo Histórico. Legajo n. ${ }^{\circ}$ 85. Inventarios, doc. 4. Apéndice Documental, doc. 1.

67. PaZ y Meliá, Antonio. Serie de los más importantes..., p. 268. 
obvio que se consumieron al final del banquete. Algunos similares pueden verse en Arte de Repostería de Juan de la Mata, editado en $1747^{68}$ (Fig. 10).

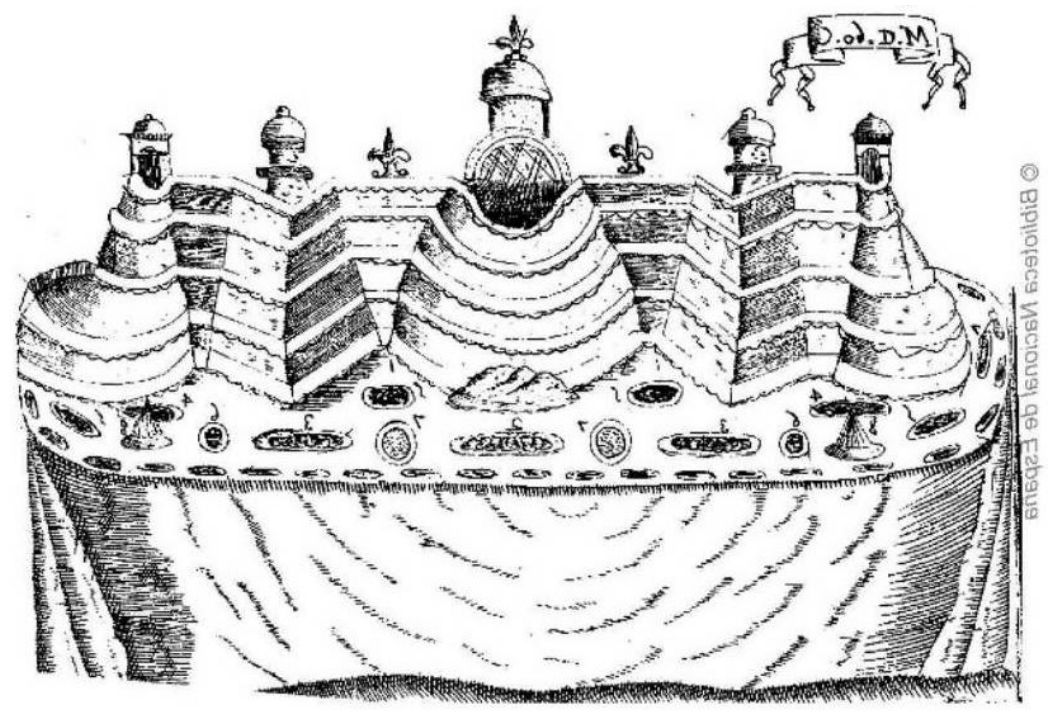

Fig. 10. Pastillage del Arte de Repostería, 1747. Juan de la Mata. Biblioteca Nacional de España, Madrid.

Conocemos que se emplearon dieciséis mesas rinconeras del color de la porcelana "que sirvieron en las piezas adonde estaban los ramilletes y mesas de leña ${ }^{69}$. Los ramilletes eran los adornos compuestos de figuras y piezas de mármol o metales labrados, que se ponían sobre las mesas en donde se servían estas comidas suntuosas, y en las que se colocaban dulces, frutas, etc.

Los festejos en la casa del marqués de Cogolludo debieron de terminarse con fuegos de artificios, mediante la construcción de una o varias máquinas de fuegos artificiales ${ }^{70}$. Estas se debieron de realizar con bastidores de lienzos ${ }^{71} \mathrm{y}$

68. MATA, Juan de la. Arte de reposteria, en que se contiene todo genero de hacer dulces secos, y en liquido, vizcochos, turrones, y natas... con una breve instruccion para conocer las frutas, y servirlas crudas, y diez mesas, con su explicacion. Madrid: Antonio Marín, 1747.

69. ADM. Sección Archivo Histórico. Legajo n. ${ }^{\circ}$ 85. Inventarios, doc. 4. Apéndice Documental, doc. 1.

70. «En esta pieza estan colocadas 24 mesas de pino quadradas dadas de color de tinte de Brasil que sirvieron en la habitacion principal la noche de la función para el fuego». ADM. Sección Archivo Histórico. Legajo n. ${ }^{\circ}$ 85. Inventarios, doc. 4. Apéndice Documental, doc. 1.

71. "62 largueros para dichos bastidores (el uno roto)». ADM. Sección Archivo Histórico. Legajo n. ${ }^{\circ} 85$. Inventarios, doc. 4. Apéndice Documental, doc. 1. 
tablas recortadas ${ }^{72} \mathrm{y}$, aunque desconocemos los posibles diseños, nos consta que debieron de tener fuentes ${ }^{73}$. Al encender por la noche los fuegos estos parecerían verter el agua del color del fósforo durante el tiempo que durase el espectáculo. En definitiva, estas secuencias ígneas nos desvelan cómo los fuegos artificiales fueron también un arte puesto al servicio del poder $^{74}$.

En 1789 con ocasión de la exaltación al trono de los reyes Carlos IV y María Luisa de Parma, la fachada del palacio de Cogolludo volvería a engalanarse. Esta vez el ornato corrió a cargo del académico de San Carlos de Valencia Felipe Fontana, y la escultura se debió a la mano de los profesores José Ginés y Anselmo Doret (Fig. 2). Esta decoración es descrita por el bibliógrafo Sempere y Guarinos, quien dirige una dura crítica a este ornato por considerarlo recargado. Merece la pena citarlo:

Tan grande acumulación de cosas (de que la vista hubiera gozado mejor, hallando descansos) obligó a que todas las partes fuesen menudas, y de consiguiente a sacrificar la grandiosidad y esbelteza de la Arquitectura. La estampa da una idea de la obra. En este caso nos inclinamos a creer que el arquitecto procediese a su pesar, obligado de las circunstancias del sitio, o de otras causas más poderosas, y no de que adoptase como mejores algunos exemplos modernos, en cuyo estilo se desconocen las proporciones, la magestad y la sencillez de los Antiguos. A un arquitecto no solo se le puede negar el conocimiento de las máximas fundamentales del arte y del poco valor que tiene la autoridad de otros Arquitectos, quando han procedido contra las reglas dictadas por la razón y el buen gusto: de otra suerte, la autoridad desnuda de raciocinio haría el mismo daño en las bellas Artes, que tanto tiempo ha hecho en la Filosofía. Este es nuestro sentir: si fuese culpado de algo más que de error, atribuyase a nuestra lisura genial, y al derecho que el público adquiere, quando se expone una obra, de juzgarla con imparcialidad, con indulgencia para el Artífice, y con respeto al Dueño ${ }^{75}$.

De ello se infiere que el crítico valenciano aboga por otra disposición más desahogada y, quizá, más neoclásica como las firmadas por Juan de Villanueva para el mismo evento. Sin duda, la casa del marqués de Cogolludo no estaba en la vanguardia del nuevo gusto imperante debido a esa reutilización de elementos empleados en los adornos de 1785 , lo que refleja esas prácticas de reciclaje frecuentes en las decoraciones efímeras.

72. "95 tabletas para dichos bastidores». ADM. Sección Archivo Histórico. Legajo n. ${ }^{\circ}$ 85. Inventarios, doc. 4. Apéndice Documental, doc. 1.

73. "6 cubetos grandes de madera que sirvieron para deposito de las aguas para las fuentes». ADM. Sección Archivo Histórico. Legajo n. ${ }^{\circ}$ 85. Inventarios, doc. 4. Apéndice Documental, doc. 1.

74. Mínguez Cornelles, Víctor y Rodríguez Moya, Inmaculada. «Un imperio iluminado por un sol y cien mil luminarias». En Mínguez Cornelles, Víctor y Rodríguez Moya, Inmaculada (dirs.). Visiones de un Imperio en Fiesta. Madrid: Fundación Carlos de Amberes, 2016, pp. 9-30.

75. Sempere y Guarinos, J. Descripcion de los ornatos públicos con que la Corte de Madrid ha solemnizado la feliz exaltación al trono de los reyes..., p. 32. 
¿Cómo se organizó la fachada? En el primer cuerpo, decorado con una franja de almohadillado clásico, se abrió un arco en el centro donde se colocó la estatua de Hércules y encima un león durmiendo en bajorrelieve "símbolo de la España por la paz que goza ${ }^{76}$. En los entrepaños de las seis ventanas se dispusieron dos tableros con escenas de guerra y dos pastoriles y en las dos restantes y unos colgantes de frutas y flores. Las ventanas estaban adornadas con cortinas de damasco carmesí guarnecidas con glasé de oro. Este cuerpo quedaba rematado con un antepecho tallado a modo de galería donde se pusieron, a la derecha, las estatuas de la Magnanimidad y la Justicia y, a la izquierda, las de la Templanza y la Magnificencia.

El segundo cuerpo se articulaba con dobles pilastras de orden corintio y en el centro un frontispicio triangular formado por dobles columnas corintias. En él se colocó una gran cortina en la que dos famas, acompañadas de varios niños, sostenían y admiraban los retratos reales realizados en medio relieve. A los lados, entre las columnas extremas, las estatuas de la Fortaleza y la Prudencia con dos bajorrelieves superiores que representaban las concordias de Himeneo y de la Paz y la Justicia. El escudo con las cifras de los nombres reales ocupaba el tímpano, acompañado por otras dos famas. Este segundo cuerpo se remataba con cuatro estatuas al plomo de las columnas, al lado derecho la Inteligencia y el Celo, al izquierdo el Mérito y el Premio. Encima de las ventanas se colocaron medallas circulares en bajorrelieve con las empresas políticas de Saavedra: "La una era la puerta del tomo primero con el lema: Excecat caudor; la tercera la decimoctava del tomo primero con el lema: a Deo, y la cuarta la vigesimoctava del referido tomo primero con el lema: Quae sint, quae fuerint, quae mox venturae trabuntur ${ }^{77}$. Por encima corría un friso con guirnaldas.

Una balaustrada remataba la fachada, interrumpida de pedestales sobre el macizo de las pilastras, que se decoraba con parejas de estatuas: la Nobleza y la Abundancia, la Sabiduría y la Felicidad Pública, la Piedad y la Sinceridad, la Virtud y la Providencia. Las basas, los capiteles y otras partes talladas (colgantes de frutas, cabezas de leones, tiestos de flores, etc.) imitaban mármoles blancos, todo lo restante se hizo con piedra berroqueña. Lúcidos cortinajes carmesíes, guarnecidos de oro, y quince arañas de cristal, junto con setenta hachas, iluminaban cada noche la fachada.

\section{NOTA FINAL}

Prestar atención al fenómeno de la fiesta en la Edad Moderna nos acerca incuestionablemente al valor que tuvo la celebración de actos públicos como

76. PaZ y Meliá, Antonio. Serie de los más importantes..., p. 264.

77. PaZ y Meliá, Antonio. Serie de los más importantes..., p. 265. 
recurso persuasivo en la reafirmación del poder de la monarquía absoluta. Estos espectáculos claramente propagandísticos reforzaban la imagen del monarca y de sus satélites, es decir, la nobleza. Así, la casa ducal de Medinaceli, a través de su primogenitura, la del marqués de Cogolludo, se unió en las diferentes ocasiones en las que hubo necesidad de exaltar, con un programa meditado y planificado, el valor del universo borbónico. Los dobles enlaces de los infantes de España y Portugal de 1785 y la subida al trono de Carlos IV y María Luisa de Parma fueron la excusa para manifestar su vínculo al soberano y a la casa real.

El palacio de los marqueses de Cogolludo en la calle de Atocha contribuyó a vertebrar la celebración de los actos festivos, unido al proceso de configuración urbana del Madrid de finales del Antiguo Régimen. De hecho, la propia transformación arquitectónica que sufrió el palacio entre 1765 y 1800 pudo surgir a instancias de los intereses derivados de las fiestas celebradas en la corte y por el cambio de la imagen del viario que experimentó la calle de Atocha.

Ha quedado demostrado cómo el marqués de Cogolludo desplegó todo su poder y magnificencia en la imagen exterior e interior de su palacio, en $1785 \mathrm{y}$ 1789. Al fin y al cabo, la morada del duque-marqués era el espejo de las virtudes y de su munificencia, donde la arquitectura, las artes decorativas, la música y los fuegos de artificio construían la imagen del linaje de los Fernández de CórdobaBenavides, como prueba de su apoyo incontestable a la monarquía ilustrada.

Con todo ello, el principal mérito de este trabajo es rescatar un inventario que permanecía inédito, circunstancia que determina el carácter más descriptivo de este texto que se apoya en la relación de fiestas conservadas. La propia naturaleza del tema, al tratarse de ornatos efímeros, no ha dificultado mayormente su análisis y ha permitido establecer aspectos más generales relacionados con el gusto de una época que oscila entre el barroco-rococó y la Ilustración. Por otro lado, se ha constatado la costumbre de reciclar los escenarios efímeros, circunstancia que explica que los ornamentos del palacio de Cogolludo de 1789 fuesen vistos como elementos demodé al reaprovechar las alhajas de 1785 .

\section{BiBLIOGRAFÍA}

AA. VV. Madrid hasta 1875: testimonios de su historia. Madrid: Publicaciones Municipales, 1980.

ÁGREDA PINO, Ana María. "Entelar el muro: los revestimientos textiles en la arquitectura occidental». En GómeZ URDÁÑEZ, Carmen (coord.). Sobre el color en el acabado de la arquitectura histórica. Zaragoza: Universidad de Zaragoza, 2013, pp. 273-330.

AlENDA Y MiRA, Jenaro. Relaciones de solemnidades y fiestas públicas de España. Madrid: Impresores de la Real Casa, 1903.

Álvarez de Miranda, Pedro. Palabras e ideas: el léxico de la Ilustración temprana en España (1680-1760). Madrid: Real Academia Española, 1992.

Benito García, Pilar. "Chinoiseries». En Carlos III. Majestad y Ornato en los escenarios del rey ilustrado. Madrid: Patrimonio Nacional, 2017, pp. 297-313. 
ALHAJAS PARA UN PALACIO EN MADRID. ESCENOGRAFÍAS EFÍMERAS EN LA CASA DEL MARQUÉS...

Bonet Correa, A. «La última arquitectura efímera del Antiguo Régimen. Estudio Introductoriom. En Descripción de los ornatos públicos de Madrid en la Coronación de Carlos IV. Barcelona: Gustavo Gili, 1983.

BONET CORREA, A. Fiesta, poder y arquitectura: aproximación al Barroco español. Madrid: Akal, 1990.

Bonet CORREA, A. «La arquitectura efímera del barroco en España». Norba. Revista de Arte, 1993, 13, pp. 23-70.

BotTineau, Yves. L'art de la cour dans l'Espagne des Lumières 1746-1808. París: Éditions De Boccard, 1986.

CARrete, Juan et al. Catálogo del Gabinete de Estampas del Museo Municipal de Madrid, vol. 1. Madrid: Ayuntamiento de Madrid, 1985.

Del Riego NúÑez, Eugenio Antonio. Poesías a las Reales Bodas de los Serenísimos Señores Infantes de España y Portugal. Madrid: Imprenta Real, 1785.

Díaz Borque, José María. Los espectáculos del teatro y de la fiesta en el siglo de Oro español. Madrid: Ediciones del Laberinto, 2002.

GÁlLEGO, Julián. "El Madrid de los Austrias: un urbanismo de teatro». Revista de Occidente, 1969, XXV, pp. 19-54.

GARMA Y DuRÁN, Francisco Javier. Theatro universal de España: descripción eclesiástica y secular de todos sus reynos y provincias, tomo IV. Barcelona: Mauro Martí, 1751.

GAYA NUÑO, Juan Antonio. La arquitectura española en sus monumentos desaparecidos. Madrid: Espasa-Calpe, 1961.

Gómez, Jesús. «Una conversación sobre la entrada real de Carlos III». Edad de Oro, 2007, XXXVI, pp. 267-286.

GonZÁlez Palacios, Alvar. Luigi Valadier. Nueva York: The Frick Collection, 2018.

Guerra y Gazola, Antonio. Resumen de las sentencias y metros, que con motivo de los felices desposorios de los señores Don Juan, Infante de Portugal, con Doña Carlota Joaquina, Infanta de España, y D. Gabriel Antonio, Infante de España, con Doña Maria Ana Victoria, Infanta de Portugal, se han colocado en varias casas de las adornadas en la carrera que anduvo S.M. y AA. el dia 29 de Marzo de ida al Santuario de Atocha, y vuelta á su Real Palacio. Madrid: Imprenta Real, 1785.

Herrero, María Jesús. «Dessert del Príncipe Carlos (Carlos IV)». En García Fernández, María Soledad (ed.). Tres siglos de formas y objetos en los palacios y monasterios reales. En torno a la mesa. Madrid: Patrimonio Nacional, 2000.

LARRIBA, Elisabel. "De l'usage de la gravure dans le Memorial literario (1784-1808)». El Argonauta Español, 2008, 5. [En línea] https://journals.openedition.org/argonauta/954 [Consultado el 21 de marzo de 2020].

Lopezosa Aparicio, Concepción. "La residencia del duque de Lerma en el Prado de San Jerónimo, traza de Gómez de Mora». Madrid, Revista de Arte, Geografía e Historia, 1998, 1, pp. 457-485.

LOPEZOSA APARIcio, Concepción. "Fiesta oficial y configuración de la ciudad. El caso del madrileño Paseo del Prado». Anales de Historia del Arte, 2002, 12, pp. 79-92.

Martín, Fernando. A. "Etiquetas y servicios en la Mesa Real». En GarCía Fernández, María Soledad (ed.). Tres siglos de formas y objetos en los palacios y monasterios reales. En torno a la mesa. Madrid: Patrimonio Nacional, 2000.

Martínez Medina, África. «La vivienda cortesana madrileña en el Reinado de Carlos III». En SAmbricio, Carlos (ed.). Carlos III, Alcalde de Madrid (1788-1988). Madrid: Ayuntamiento de Madrid, 1988. 
MATA, Juan de la. Arte de reposteria, en que se contiene todo genero de hacer dulces secos, $y$ en liquido, vizcochos, turrones, y natas... con una breve instruccion para conocer las frutas, y servirlas crudas, y diez mesas, con su explicacion. Madrid: Antonio Marín, 1747.

Mínguez Cornelles, Víctor y RODRíguez mOYA, Inmaculada. «Un imperio iluminado por un sol y cien mil luminarias». En Mínguez CORnElles, Víctor y Rodríguez MoYA, Inmaculada (dirs.). Visiones de un Imperio en Fiesta. Madrid: Fundación Carlos de Amberes, 2016, pp. 9-30.

MONTES SERrAnO, Carlos. "El problema del estilo en la arquitectura madrileña del siglo XVIII». En SAmBricio, Carlos (ed.). Catálogo de la Exposición de Carlos III. Alcalde de Madrid (1788-1988). Madrid: Ayuntamiento de Madrid, 1988, pp. 449-478.

Morales Roca, Francisco José. "Mercedes concedidas con motivo de la exaltación al trono del Rey Carlos IV. Su entrada en Madrid, celebración de Cortes Generales y jura de don Fernando, Príncipe de Asturias (1. ${ }^{a}$ parte: Nobiliarias)». Hidalguía: la Revista de Genealogía, Nobleza y Armas, 2004, 304-305, pp. 463-474.

Morales RocA, Francisco José. «Mercedes concedidas con motivo de la exaltación al trono del Rey Carlos IV. Su entrada en Madrid, celebración de Cortes Generales y jura de don Fernando, Príncipe de Asturias (2. ${ }^{a}$ parte: Nobiliarias)». Hidalguía: la Revista de Genealogía, Nobleza y Armas, 2006, 319, pp. 835-874.

NAVASCuÉs PALACIO, Pedro. "Sobre titulación y competencia de los arquitectos de Madrid (1775-1825)». Anales del Instituto de Estudios Madrileños, 1975, 11, pp. 123-136.

NAVAscuÉs PAlacio, Pedro. Palacios madrileños del siglo XVIII. Madrid: Artes Gráficas Municipales, 1978.

PAZ y Melí, Antonio. Serie de los más importantes documentos del archivo y biblioteca del Exmo. Señor duque de Medinaceli. 1. ${ }^{a}$ Serie Histórica. Madrid, 1915.

PÉrez Magallón, Jesús. Construyendo la modernidad de la cultura española en el tiempo de los novatores (1675-1725). Madrid: CSIC, 2002.

PÉREZ Monzón, O. "Ceremonias regias en la Castilla medieval. A propósito del llamado libro de la Coronación de los Reyes de Castilla y Aragón». Archivo Español de Arte, 2010, 332, p. 319.

ReEse, Thomas Ford. The architecture of Ventura Rodriguez, vol. 1. Nueva York, 1976.

RiBera, Manuel Mariano. Genealogía de la Nobilissima familia de Cervellón. Barcelona: Pablo Campins, 1733.

RODRÍGUEz MOYA, Inmaculada. "Tres siglos de máquinas ígneas. Los fuegos de artificio en los festejos de la Monarquía Española, siglos XVI al XVIII». En RODRÍGuEZ MoYA, Inmaculada (ed.). El Rey festivo. Palacios, jardines, mares y ríos como escenarios cortesanos (siglos XVI-XIX). Valencia: Universitat de València, 2019, pp. 153-174.

Rodríguez Ruiz, Delfín. "Los lenguajes de la magnificencia: la arquitectura madrileña durante el reinado de Carlos III». En SAmBricio, Carlos (ed.). Carlos III, Alcalde de Madrid (1788-1988). Madrid: Ayuntamiento de Madrid, 1988, pp. 265-280.

SAmbricio, Carlos. "Fiesta en Madrid durante el reinado de Carlos III». En SAmbricio, Carlos (ed.). Catálogo de la Exposición de Carlos III, Alcalde de Madrid (1788-1988). Madrid: Ayuntamiento de Madrid, 1988, pp. 575-628.

SÁnchez GonzÁlez, Antonio. "Baronía de los Moncada en los Reinos de la Corona de Aragón: Fondos documentales inéditos para su estudio». Aragón en la Edad Media, 2008, XX, pp. 737-755. 
RAÚL ROMERO MEDINA

ALHAJAS PARA UN PALACIO EN MADRID. ESCENOGRAFÍAS EFÍMERAS EN LA CASA DEL MARQUÉS...

SÁnchez GonZÁlez, Antonio (ed.). El arte de la representación del espacio. Mapas y planos de la colección Medinaceli. Huelva: Universidad de Huelva, 2017.

SANCHO, José Luis. «Vestir palacio a la moda. Carlos III y el amueblamiento textil del Palacio Real de Madrid». Archivo Español de Arte, 2000, 290, pp. 117-131.

SANCHO José Luis. «Tan perfectas como corresponde al gusto y grandeza de sus Majestades». Las artes en la corte de Carlos IV». En SANCHO, José Luis et al. (eds.). Carlos IV, mecenas y coleccionista. Catálogo de la Exposición. Madrid: Patrimonio Nacional, 2009, pp. $15-52$.

SANCHO, José Luis. "Función y decoro. El mobiliario del palacio real de Madrid bajo Carlos III. Libros de la Corte, 2018, 10, pp. 258-310.

Sempere y Guarinos, J. Descripcion de los ornatos públicos con que la Corte de Madrid ha solemnizado la feliz exaltación al trono de los reyes nuestros señores Carlos IIII y Doña Luisa de Borbon y la jura del serenisimo señor Don Fernando, Principe de Asturias. Madrid: Imprenta Real, 1789.

SimÓn PALMER, María del Carmen. «Evolución del gusto en la Mesa Real». En GARCía FernánDEZ, María Soledad (ed.). Tres siglos de formas y objetos en los palacios y monasterios reales. En torno a la mesa. Madrid: Patrimonio Nacional, 2000.

Sociedad Española de Amigos Del ARTe. Exposición del Antiguo Madrid. Catálogo General Ilustrado. Madrid: Gráficas Reunidas, 1926.

Sото CABA, Victoria. "Fiesta y ciudad en las noticias sobre la proclamación de Carlos IV". Espacio. Tiempo y Forma, Serie VII, Historia del Arte, 1990, 3, pp. 259-271.

Soto CABA, Victoria. El barroco efímero. Madrid: Historia 16, Cuadernos de Arte Español, 1992.

\section{REFERENCIAS DOCUMENTALES}

ADM. Archivo Ducal de Medinaceli (Toledo)

ADV. Archivo de la Villa (Madrid)

\section{ApÉNDICE DOCUMENTAL}

Para su transcripción hemos seguido los siguientes criterios:

1. Las abreviaturas se desarrollan o desatan ( $\mathrm{SE}=$ su excelencia). Las letras omitidas se transcriben en cursiva $\left(n .^{\circ}=\right.$ número).

2. Se transcribe todo lo que aparece en el texto.

3. Se han colocado signos de puntuación modernos. No se acentúan las palabras, salvo que lo estén en el documento original. Las mayúsculas y minúsculas se corrigen de acuerdo con las normas actuales de ortografía. Las palabras indebidamente concatenadas y separadas se separan o se unen según el sistema actual vigente.

4. Se transcribe literalmente respetando el uso de la z por c, la g por la j o la $\mathrm{x}$ por la $\mathrm{j}$. 
RAÚL ROMERO MEDINA

ALHAJAS PARA UN PALACIO EN MADRID. ESCENOGRAFÍAS EFÍMERAS EN LA CASA DEL MARQUÉS...

\section{DOCUMENTO 1}

Año de 1785

Inventario de las alhajas que se utilizaron para la decoración del palacio del duque de Santisteban en Madrid, con motivo de las bodas de los infantes de España y Portugal.

ADM. Sección Archivo Histórico. Legajo n. ${ }^{\circ}$ 85. Inventarios, doc. 4.

Lista de las alaxas que sirvieron para la funcion que dio el Excelentisimo Señor duque de Santistevan marques de Cogolludo mi señor con motivo de la exaltacion al trono de sus Magestades (que Dios guarde).

Colgaduras, cortinages que sirvieron para la seis piezas del quarto vaxo.

Quarenta y cinco sobre puertas de tafetan blanco guarnecidas de glase de oro.

Ochenta y nueve cortinas blancas de tafetan guarnecidas de glase dorado. brichos.

Sesenta y tres paños de tafetanes de varios colores bordado de platillas y

Una porcion de tiras de varios tafetanes bordados que sirvieron de frisos.

Otra porcion de retales menudos de diferentes tafetanes vordados que sirvieron de añadiduras para las colgaduras, las cuales estan colocadas de la casa de San Pedro en el quarto de su excelencia a espaldas de la pieza de chimenea, en donde estan igualmente las flores que sirvieron de adorno a las colgaduras colocado todo entre arcones.

Primera. Señalada con el numero 1 contiene dentro de dicha arca todas las flores y colgantes de cintas que sirvieron de adorno a las colgaduras del quarto vajo. En esta misma arca estan los 16 arboles frutales que sirvieron en el deser de las fuentes.

Segunda arca señalada con el numero 2 contiene dentro las 45 sobrepuertas guarnecidas de glase de oro. 89 cortinas blancas guarnecidas de lo mismo.

Una alfombra o paño de glase de oro moetada guarnecida con dos ordenes de galon de oro vrillante con 8 borlas de oro colocadas en sus extremos; cuia alfombra sirvio ansi la noche que su excelencia dio la funcion.

Dos cubiertas de sillas de tafetan blanco guarnecidas de dos ordenes de galon de oro vrillantes que sirvieron para sus Magestades.

Dos cubiertas para sillico de damasco carmesi guarnecidas de galon de oro brillante.

Terzera arca señalada con el numero 3 contiene 63 paños grandes de tafetanes bordados de brichos. Una porcion de varios tafetanes con distintos colores que sirvieron de friso en las colgaduras.

19 voliches sobrantes para vorlas. 
ALHAJAS PARA UN PALACIO EN MADRID. ESCENOGRAFÍAS EFÍMERAS EN LA CASA DEL MARQUÉS..

Piezas de glase de oro que se quitaron de varios cortinajes que sirvieron en la funcion.

Una porcion de vorlitas de plata y oro falso que servian de colgantes en las mismas piezas.

8 pertierros que sirvieron de figuras el paseo del deser de las fuentes.

16 papeles diferentes vrichos sobrantes de los bordados de las colgaduras.

En este mismo quarto alredor de sus paredes estan colocadas las 32 arandelas finas dadas de color con sus flores imitando china.

En otra pieza estan colocadas 102 arandelas dadas de color de porzelana de diferentes mecheros que asi estas como las anteriores sirvieron en el cuarto bajo.

12 acheres grandes de tres mecheros.

10 acheros con su mechero que sirvieron en la fachada.

43 sobrepuertas de madera dadas de color de porzelana con sus varillas y tornillos que sirvieron en el quarto bajo.

26 garruchas de madera que sirvieron para subir los adornos de la fachada y salón.

19 tiros de soga de cañamo de diferentes tamaños que sirvieron para la expresada fachada y salón.

15 caños de oja de lata que sirvieron para el recogimiento de las aguas de los texados.

\section{Fontarras}

En dicho quarto estan custodiadas igualmente las 12 llabes de paso y las 3 de cajetillas los plaios de las cubas con todas sus cañerias de plomo.

Cuarto de su excelencia

Primera pieza de entrada

En dicha pieza estan colocadas los cinco tableros del deser que sirvio con las fuentes; contiene 4 vasas con sus grupos, 14 fuentes y 2 grupos, 16 arboles, 8 pertierros, un templo en el medio sostenido de 8 columnas.

11 figuras grandes del templo, 77 vasos, 110 figuras estatuarias y 74 figuras con traxes cuias figuras con las columnas de templo estan colocadas en la misma pieza en su cajon señalado con el numero 2.

Pieza de la chimenea del quarto de su excelencia

En esta pieza estan colocados los seis colgantes o trofeos que sirvieron de adorno en la fachada y una cora.

Pieza antes del oratorio entrando por la de la chimenea a mano derecha estan colocadas tres piezas del deser nombrado el maio, contiene un grupo en el medio con 66 figuras y 34 pedestales con las fichas y 2 maios.

Estas figuras estan colocadas en su cajon numero 4 devajo de sus tableros.

En esta misma pieza a mano izquierda estan colocados los cinco tableros del deser nombrado la feria. Se compone de 18 vasas con sus vasos 76 trajes españoles y de otras clases, varias mesitas de quinqalleria y una glorieta con su pirámide. 
En dicha pieza estan colocados los cuatro medallones y un león que sirvieron de adorno en la fachada.

En la pieza llamada el quarto oscuro estan colocados los cinco tableros del deser nombrado el vacanal, contiene 56 figuras de traxes, 43 figuras del grupo del medio con su emparrado, dos piramides y 2 bailes de bacantes, 44 basas con sus pedestales.

\section{Nota}

Faltan dos figuras y un pedestal y lo restante esta colocado en su cajon.

En esta misma pieza esta un cajoncito que contiene varias piezas sobrantes de los quatro deseres, pues los dos restantes fueron en pastillajes.

En esta misma pieza estan colocadas las 16 mesitas de rinconeras dadas de color de prozelana que sirvieron en las piezas adonde estaban los ramilletes y mesas de leña.

En la pieza o arco que da paso a la tribuna estan colocadas 7 de las estatuas que sirvieron en la fachada con el Ercules que estaba al paso de la puerta principal.

\section{Antecamara}

En esta pieza estan colocadas 24 mesas de pino quadradas dadas de color de tinte de Brasil que sirvieron en la habitacion principal la noche de la función para el fuego.

Guardarropa de la casa de San Pedro

En dicho guardarropa quedan apiladas todas mesas con sus pies que sirvieron para la funcion señaladas con su numero.

En dicho quedan apilados 87 banquillos que sirvieron para anudar las colgaduras de las salas.

62 largueros para dichos bastidores (el uno roto).

95 tabletas para dichos bastidores.

3 mesas de fregadero.

5 pares de pariguelas las dos grandes con su cajon.

6 cubetos grandes de madera que sirvieron para deposito de las aguas para las fuentes.

Arañas de christal nuevas.

En la casa de San Pedro se hallan guardadas 22 arañas nuevas en la alcoba principal de su excelencia.

En la casa de excelencia calle de Atocha quedan puestas en el salon y demas piezas de la casa 27 arañas que componen 49 arañas las que tiene SE en sus dos casas.

La franquizia que su Majestad dio al su excelencia para la entrada de dichas arañas fue hasta el numero de 51. 
ALHAJAS PARA UN PALACIO EN MADRID. ESCENOGRAFÍAS EFÍMERAS EN LA CASA DEL MARQUÉS...

Lo que recibio el guardaropa del comisionado fueron 50 con que devera dicho comisionado responder a ella.

Al embaxador de Portugal presto su excelencia arañas para su funcion y quebraron una de las nuevas y no sea buelto. Su excelencia mandara lo que sea de su agrado.

En el día 8 de julio entregue al guardaropa de la casa del Prado de orden del duque mi señor 49 cortinas de tafetan blanco guarnecida en gasa dorada.

10 sobrepuertas de tafetan encarnado guarnecidas de la misma gasa que las cortinas.

36 borlas de plata y 19 sobre puertas de madera color de blanco esto es para el salon que SE mando adornar para el combite que ha de tener el domingo 10 de este de la fecha.

Vedoyas

En 9 de dicho se llevo a la casa de su excelencia en el Prado el deser del piramide y el de la feria con todas las figura y con 20 mas de china blancas del ramillete del deser de las fuentes.

Vedoyas 
